\title{
A new genus of semislugs (Stylommatophora: Euconulidae) from Costa Rica and a review of the genus Velifera (Stylommatophora: Euconulidae)
}

\author{
Zaidett Barrientos \\ Laboratorio de Ecología Urbana, Universidad Estatal a Distancia, 2050 San José, Costa Rica; \\ zbarrientos@uned.ac.cr
}

Received 02-V-2019. C Corrected 04-IX-2019. Accepted 24-IX-2019.

\begin{abstract}
Introduction: The family Euconulidae is circumglobal, but only one subfamily, the Euconulinae, occurs in the American continent. Fourteen native euconulids, in three genera, have been reported from Costa Rica. Objective: In this paper I describe Tikoconus, a new genus of Euconulinae endemic to Costa Rica. Methods: I dissected alcohol-preserved euconulids collected in Costa Rica. I took photographs or electron micrographs or drew the shell, external anatomy, reproductive system, mantle cavity organs and radula. Results: The genus Tikoconus can be recognized by its semislug appearance and very thin and often flexible subglobose to subglobose-depressed external shell. Other distinctive features of the genus are a lack of black dots on the mantle and the presence of at least some dark blotches on the subpedal groove band. Internally, the urethra has a Z-shaped prolongation that almost reaches the mantle collar. The reproductive system has a distinctive external C-shaped penial gland that surrounds half of the penis circumference and is attached to the penis and to the penial caecum, but not connected to them by ducts. Also, there is an internal mono- or bi-lobulated extension in the penis. The epiphallus has a verge that enters into the penis. The penial sheath surrounds part of the penis, the epiphallus base and the penial retractor muscle insertion, but leaves the penial gland and the penis caecum free. The gametolytic gland is absent. I described two new subgenera: Tikoconus with six new species- $T$. (T.) costaricanus sp.n. (type species), T. (T.) onca sp.n., T. (T.) andresi sp.n., T. (T.) katyae sp.n., T. (T.) alosii sp.n., T. (T.) subsilvanus sp.n.; and Bribriconus with only one species-T. (B.) thompsoni sp.n. All species have restricted distributions and are endemic to particular watersheds, except for T. costaricanus which occurs nearly throughout the central mountains of Costa Rican. This genus inhabits very wet, little disturbed tropical forests from 400 to 2500 masl on the Atlantic slope and from 760 to 2500 masl on the Pacific slope. The genus Velifera, the other semislug euconulid reported from Costa Rica, is kept as a valid taxon and I choose the specimen ANSP 48765 as lectotype of Velifera gabbi with the purpose of clarifying the application of the name to a taxon. Conclusion: A new euconulid genus and seven species were described.
\end{abstract}

Key words: Euconulinae, land snail, semislug, endemism, snail anatomy.

Barrientos, Z. (2019). A new genus of semislugs (Stylommatophora: Euconulidae) from Costa Rica and a review of the genus Velifera (Stylommatophora: Euconulidae). Revista de Biología Tropical, 67(6), 1313-1358.

Costa Rica is well known for its high biodiversity and exuberant forests, nevertheless land snail populations are quite small in most of the country. Even the earlier naturalists had problems with European malacologists, who refused to believe the extreme rarity of most land snails (Hilje Quirós, 2013). Besides this, the natural darkness of the forest and the frequent rain make searching for snails very difficult. Therefore, collectors often focus their work on soil samples examined in the laboratory. In consequence, most collections consist 
of empty shells. Groups, like the family Euconulidae, that need anatomical analysis of soft parts have been overlooked.

Currently the taxonomic level and relationships assigned to Euconulidae vary according to the author. Baker (1928) created the subfamily Euconulinae, on the basis of their bi- or tricuspid marginal teeth, elongated lung, anterior position of the cloacal opening and intrusion of the right ocular retractor between the penis and vagina. He placed the Euconulinae in the family Zonitidae and included the following genera: Guppya Mörch, 1867, Euconulus Reinhard, 1883 and Habroconus Fischer \& Crosse, 1872. Later, Baker (1941) placed the Euconulinae in the family Helicarionidae. He also added several genera, including Velifera Binney, 1879 (Baker, 1941).

The group is recognized as family by Zilch (1959-1960), Bequaert and Miller (1973), Vaught (1989), Schileyko (2002a, 2002b) and Bouchet and Rocroi (2005). However, none of those authors justified such change. Only two authors accepted the group as subfamily: Pilsbry (1946), who follows Baker`s 1928 classification; and Thompson (2011), who follows Baker’s 1941 classification.

Euconulidae in the sense applied by Schileyko (2002a, 2002b) is a circumglobally distributed group of land snails with 69 genera classified in three subfamilies: Microcystinae, Euconulinae and Kaliellinae. In Schileyko's new arrangement, the genus Guppya was treated as a subgenus of Euconulus, leaving only three euconulid genera in the Americas: Euconulus, Habroconus and Velifera. In the American continent Kaliellinae is represented only by the introduced Ovachlamys Habe 1946.

Costa Rica is the only country in the Western Hemisphere in which all three native genera are reported (Barrientos, 2003). Details of the internal anatomy of Euconulus and Habroconus can be found in the literature (Baker, 1928, 1941; Schileyko, 2002a). The genus Velifera is known only from the shell, radula and general external appearance.

I have been collecting live Euconulidae specimens all over Costa Rica for about two decades and in this paper I describe a new genus with seven species.

\section{METHODS AND MATERIALS}

This research is based on specimens collected from 1993 to 2004 by the Instituto Nacional de Biodiversidad (INBio) and from 2009 to 2013 by the Universidad Estatal a Distancia, Costa Rica (UNED) (Fig. 1). All INBio specimens are now harboured in the University of Costa Rica Zoology Museum. Specimens were relaxed in freshwater for 12 hours, then fixed and preserved in $70 \%$ ETOH. I dissected the specimens with aid of a Zeiss $(0.65-5.0 x$ /10x, 25x) stereo-microscope. Some alcoholpreserved specimens have faded or became pinkish with time. I examined a total of 1166 specimens that belong to this genus; the number of specimens examined is included at the beginning of the external anatomy section of each species.

Holotypes were not dissected because it is impossible to remove the body without destroying the shell in most species from this genus, and especially because the external colour pattern is enough for species identification. Description of new species relies on the holotypes for external characteristics and the paratypes for anatomy, radula and shell measures. I give holotype measurements as accurately as possible without destroying or removing parts of the specimen. General measurements, nomenclature and abbreviations are shown in figures 2 to 5 . I measured specimens using an ocular micrometer of a Zeiss stereomicroscope at $25 \mathrm{x}$, scale $0.1 \mathrm{~mm}$.

Shell (Fig. 2): I made electron micrographs of the shell shape and sculpture. I measured the shells with the aid of a Zeiss stereo microscope ocular micrometer.

External anatomy (Fig. 3): I described the external morphology based on the holotype colour pattern and added variation of paratypes and other specimens. I also established a cephalopodium nomenclature based on the relative 


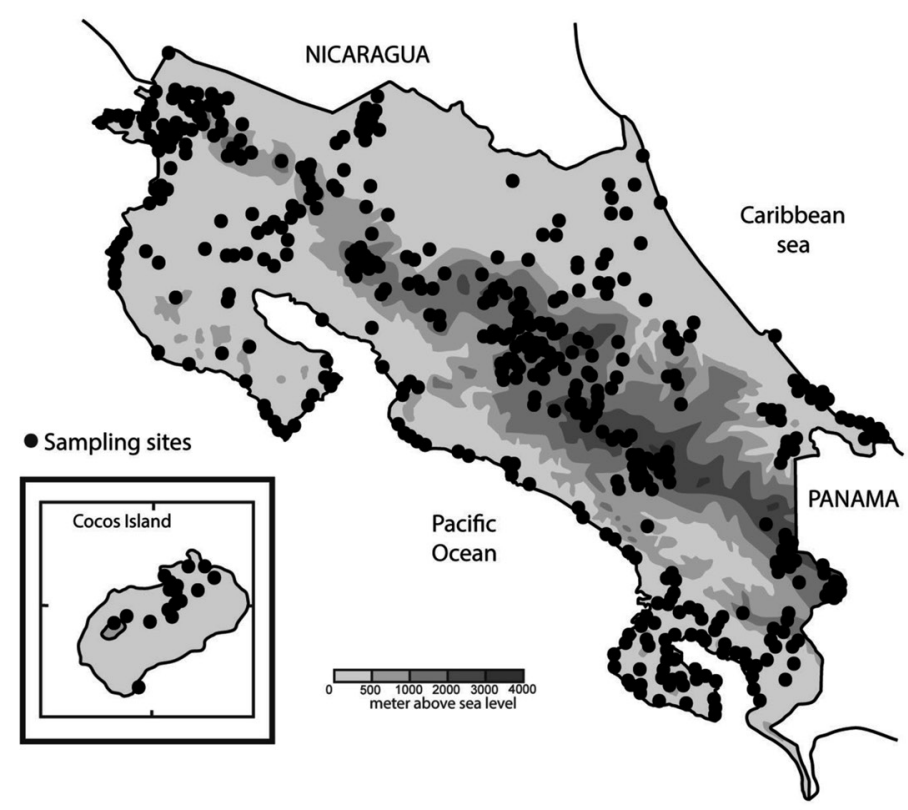

Fig. 1. Costa Rican sites surveyed for molluscs from 1993 to 2013.

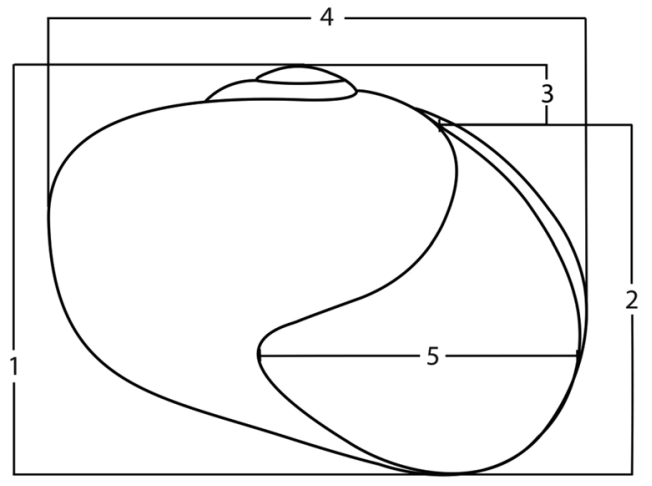

Fig. 2. Shell measurements: 1- shell height is the distance from the apex to the basal lip parallel to the shell axis, 2- aperture height is measured from the basal lip to the attachment point of the upper lip, 3- spire is measured from the point of attachment of the upper lip to the apex, 4- shell width is the greatest distance across the shell transverse to the shell axis, 5- aperture width is measured from the edge of the outer lip to the inner edge of the columellar lip transverse to the shell axis.

position of bands, lines and areas from grooves and other well-known parts of the foot.

Mantle cavity organs (Fig. 4): I dissected specimens preserved in $70 \%$ ethanol and extracted the mantle cavity organs. I made drawings based on stereomicroscope photographs and direct observation of the dissected parts. In neotropical euconulid semislugs the urethra is characteristic; therefore, in order to explain the morphology more clearly, I divided the urethra into three segments: primary urethra, middle urethra and secondary urethra. The primary urethra joins the kidney apically, but is not reflected back along the kidney's edge as in most Sigmurethra. Instead, the primary urethra projects forward nearly reaching the mantle's edge, is curved, not glandular and meets the middle urethra by a simple pore. The middle urethra is a glandular and broader duct. It is sigmoid in shape and surrounds the primary urethra's tip before running backwards, parallel to the primary urethra and kidney. It ends at the kidney's base. There is no clear division between the middle and the secondary urethra. The transition between them is gradual, marked by a loss of glandular tissue. The secondary urethra, as in most Sigmurethra, runs parallel to the rectum, ending at the mantle edge near the pneumostome (Pilsbry, 1900). The primary urethra and part of the middle urethra form the 

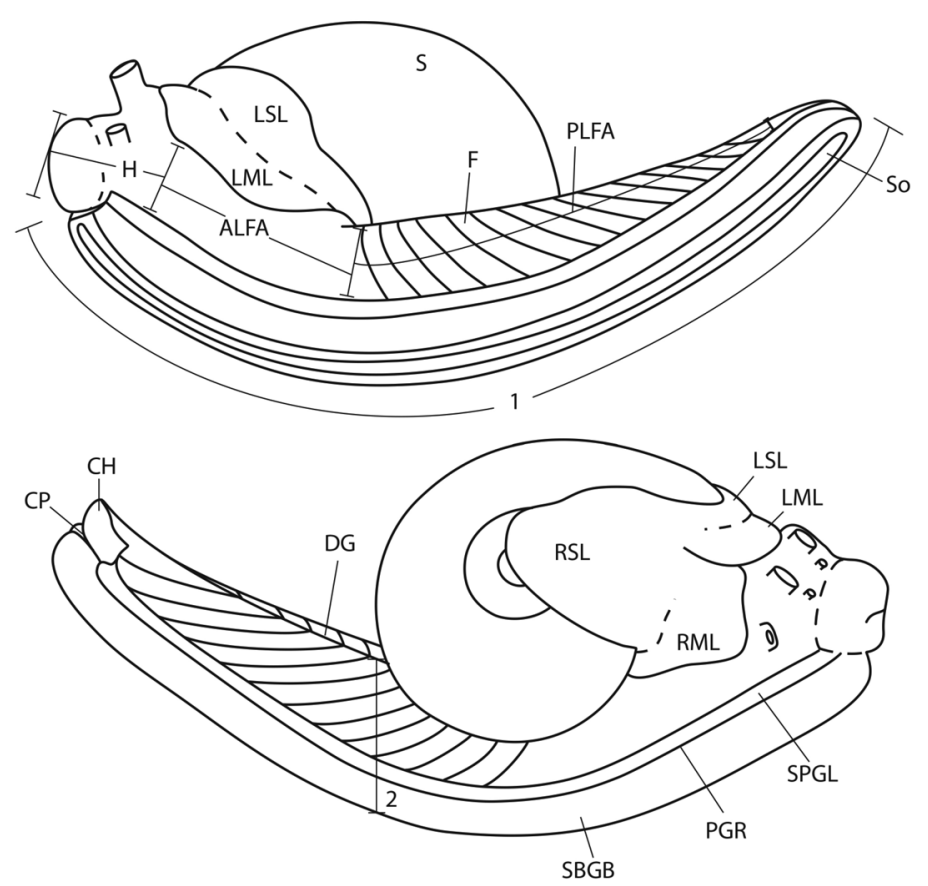

Fig. 3. Cephalopodium nomenclature and measurements. Nomenclature: ALFA- anterior lateral foot area, CH- caudal horn, CP- caudal pore, DG- dorsomedial groove, F- foot, H- head, LML- left mantle lobe, LSL- left shell lappet, PLFA- posterior lateral foot area, PGR- pedal grove, RML- right mantle lobe, RSL- right shell lappet, S- shell, So- sole, SPGL- suprapedal groove line, SBGB- subpedal groove band. Measurements: 1- cephalopodium length, 2- cephalopodium width.

urethra's projection. The kidney, primary and middle urethras form a "Z" or inverted " $S$ " shaped complex that can be viewed through the translucent shell of living specimens. Mantle extensions are also important. There are two mantle lobes that cover part of the head-the right and left mantle lobes-and two fused shell lappets that cover part of the shell-the right and left shell lappets.

Reproductive system (Fig. 5): I dissected the reproductive systems from specimens preserved in $70 \%$ ethanol. Reproductive systems were drawn using stereomicroscope photographs and personal observations of the dissected parts. For electron-microscopic analysis of the male parts, I extracted the male reproductive system from specimens preserved in $70 \%$ ethanol and dissected the atrium and penis. I put these specimens in $1 \mathrm{ml}$ of $95 \%$ ethanol for $30 \mathrm{~min}$, then in $1 \mathrm{ml}$ of $100 \%$ ethanol for another $30 \mathrm{~min}$ and finally in $0.05 \mathrm{ml}$ of Hexamethyldisilazane in an open vial until all the substance evaporated. This procedure caused some tissue dehydration, which accentuated texture and caused tissues to shrink. I measured the verge of one specimen before and after this procedure; the verge's length changed from 0.3 $\mathrm{mm}$ to $0.2 \mathrm{~mm}$.

Dentition: I dissected out the buccal mass and mouth and used a sodium hypochlorite solution to isolate the radula and jaw. Then I observed and photographed the material with an electronic microscope.

\section{Museum acronyms used in this paper}

MZUCR-INBio: National Biodiversity Institute (INBio) specimens in the Zoology Museum, University of Costa Rica. 
A
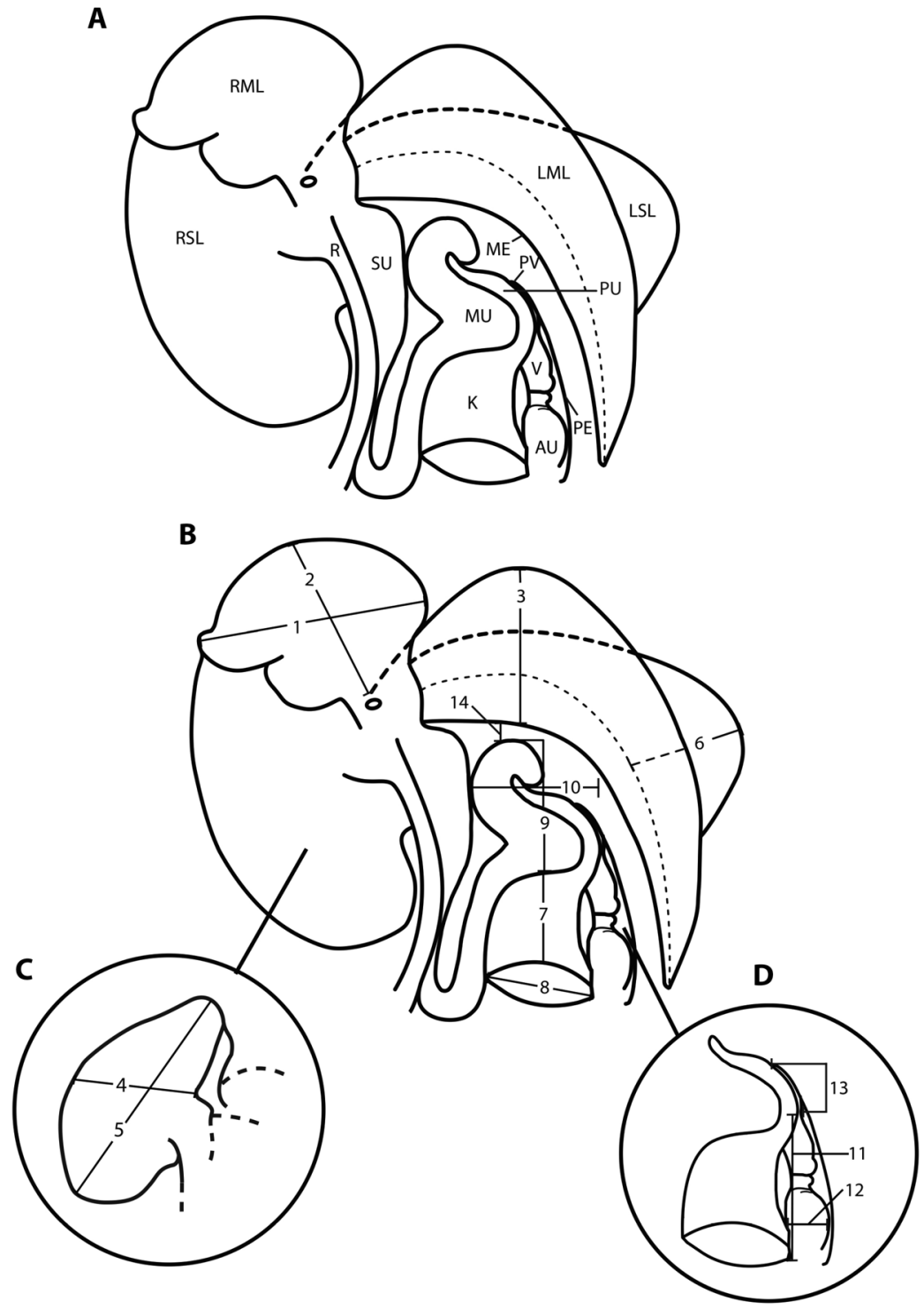

Fig. 4. Mantle cavity organs, mantle lobes and shell lappets nomenclature (A), and measurements (B). Detail (C) shows right shell lappet in an extended position. Nomenclature: AU- auricle, K- kidney, LML- left mantle lobe, LSL- left shell lappet, ME- Mantle edge, MU- middle urethra, PE- pericardium, PU- primary urethra, PV- pulmonary vein, R- rectum, RML- right mantle lobe, RSL- right shell lappet, SU- Secondary urethra, V- ventricle. Measurements: 1- RML length, 2- RML width, 3- LML width, 4-RSL width, 5- RSL length, 6-LSL width, 7- kidney length, 8- kidney width, 9- urethra`s projection length, 10- urethra`s projection width, 11- heart length, 12- heart width, 13- pulmonary vein length, 14- distance between urethra`s projection and mantle edge. 

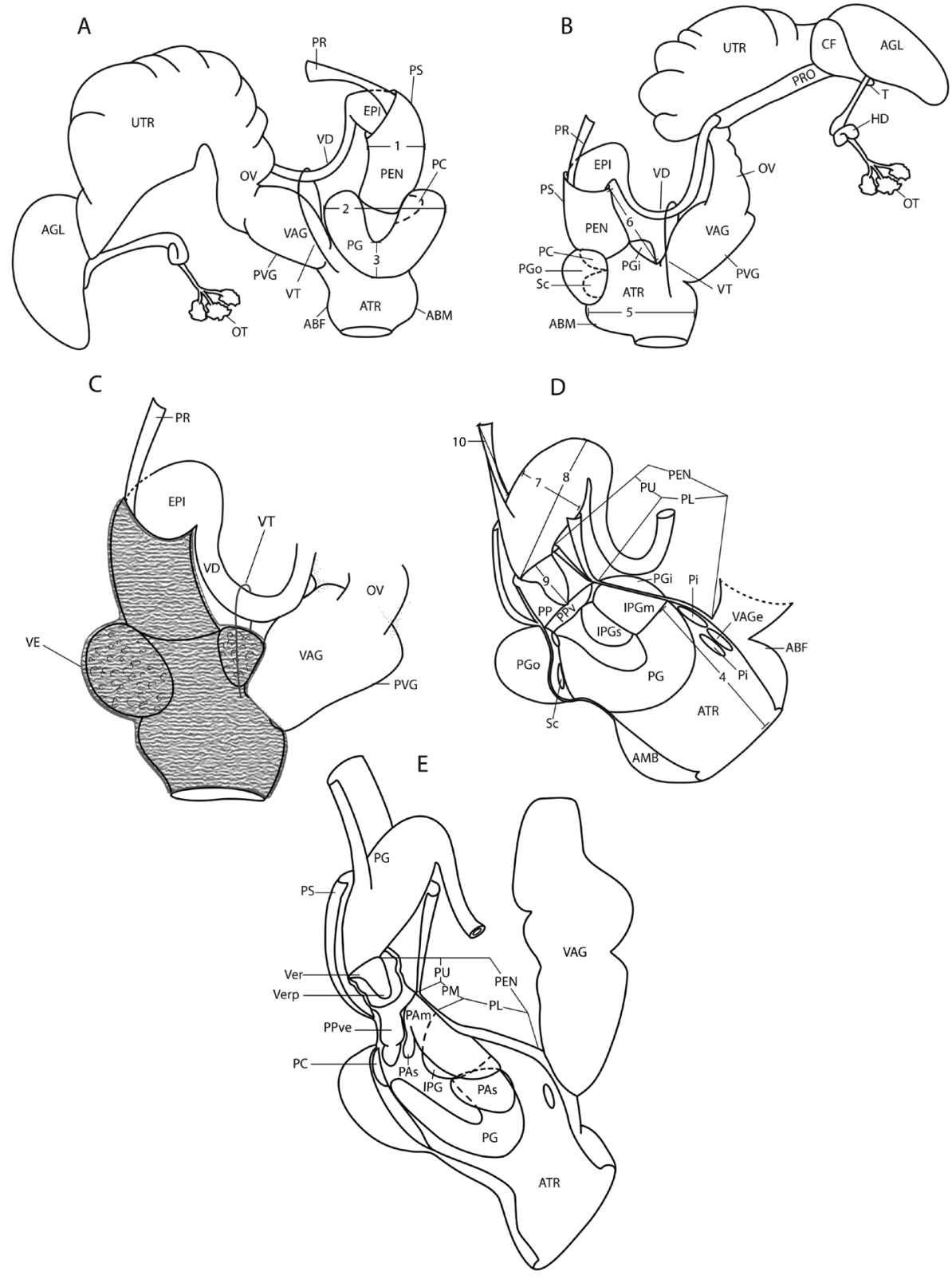

Fig. 5. Reproductive system nomenclature and measurements. A: Reproductive system front side. B: Reproductive system rear side. C: Male reproductive system covered by velum (in gray). D \& E: Dissected male reproductive system. Nomenclature: ABF- accessory bulge on female side, ABM- accessory bulge on male side, AGL- albumen gland, ATRgenital atrium, CF- Carrefour, EPI- epiphallus, HD- hermaphroditic duct, IPG- internal penial gland, IPGm- internal penial gland's main lobe, IPGs - internal penial gland's secondary lobe, OT- ovotestis, OV-oviduct, PAm- main penis pad, PAssecondary penis pad, PC- penis caecum, PEN- penis, PG- penial gland, PGi- penial gland inner end, PGo- penial gland outer end, Pi- pilaster, PL- penis lower part, PM- penis middle part, PP- prepuce, PPv- prepuce valve, PPve- prepuce valve extension, PR- penis retractor muscle, PRO- prostate, PS- penis sheath, PU- penis upper part, PVG- perivaginal gland, Scsecondary caecum, T- talon, UTR- uterus, VAG- vagina, VAGe- vagina entrance, VD- vas deferens, VE- velum, Ver- verge, Verp- verge pore, VT- velum thread. Measurements: 1- penis width, 2- penial gland length, 3- penial gland width, 4- atrium length, 5- atrium width, 6- penis length, 7- epiphallus width, 8- epiphallus length, 9- verge length, 10- penis retractor length. 
MZUCR: Zoology Museum, University of Costa Rica, Costa Rica.

CNMO: Mollusk National Collection, National Autonomous University of Mexico (UNAM), Mexico D.F.

UF: Florida Museum of Natural History, University of Florida, Gainesville, Florida, USA.

ANSP: Academy of Natural Sciences (now called 'Academy of Natural Sciences of Drexel University'), Philadelphia, USA.

Distribution and type localities: I give collection data in the following order: Country, state, locality. Altitude (in meters above sea level). Geographic coordinates. Sampling date (day/month/year). Collectors. Field note number, starting with the abbreviation for witness, testigo, (T.;), testigo is the Spanish word for field note number, which appears in all labels in the MZUCR-INBio collection. A copy of all field notes is housed at the Zoology Museum, University of Costa Rica.

Comparison with other euconulids: I also checked the euconulid collections at MZUCR, UF and ANSP. I made a detailed comparison with other euconulids based on the literature and observation of specimens. I paid special attention to Velifera gabbi ANSP 477074.

\section{RESULTS}

\section{Tikoconus, new genus}

Type species: Tikoconus costaricanus, new species.

Diagnosis: The genus Tikoconus can be identified by the following combination of external characteristics: slug-like appearance; thin, light to dark amber shell; shell partially covered by shell lappets; shell internal layer nacreous; "Z" shaped urethra projection, which is visible through shell (no dissection needed); well-developed shell lappets; absence of tiny black dots on mantle; and at least some pigmentation on the subpedal groove band.
Definitive identification of the genus requires dissection and examination of the reproductive tract, and the following characteristics are distinctive: $\mathrm{C}$-shaped penial gland; penial caecum attached to penial gland outer end, not visible without penis dissection (and even so, only with careful analysis because it collapses); internal penial gland present but variable in lobule amount; penial sheath partially covering penis and epiphallus, leaving penis caecum and penial gland free; small conic verge at epiphallus, verge enters into penis; prepuce covering verge; gametolytic gland absent; short penis retractor muscle attached to epiphallus base; translucent epiphallus with longitudinal pilasters; prostate adnate to uterus; and basal perivaginal gland.

Shell (Fig. 2, Fig. 6, Fig. 7, Fig. 8): Subglobose to depressed subglobose, yellowishgreen to dark drown, translucent, flexible to rigid, thin to very thin, wider than high. Whorls 3 to 3.5 , last whorl inflated. Shell with two easily separable thin layers: an external layer or periostracum that is very thin, corneous, and very flexible; and an internal layer that is smooth, thin to very thin, nacreous, and absent at peristome. Protoconch has 1 to 1.5 whorls, transition to teleoconch often not well defined; first quarter of whorl smooth then becoming spirally striate with 20 to 29 striae spaced 5 to $10 \mu \mathrm{m}$ apart. The width and depth of striae are uniform, although some striae are partially skipped or not well defined. Remaining whorls smooth, some with randomly scattered, small, elongated or spherical granules, poorly defined growth wrinkles. Parietal and umbilical callus lacking. Sutures slightly indented and softly crenulated. Apex short, slightly convex, approximately $1 / 5$ to $1 / 10$ shell height. Body whorl periphery evenly rounded. Aperture large, sometimes descending in frontal view, oblique, generally higher than wide. Peristome thin, flexible, not reflected, composed of periostracum only, straight to slightly curved in lateral view, parietal suture not descending in lateral view. Umbilicus imperforate, rimate or perforate, never widely umbilicate. Shell 

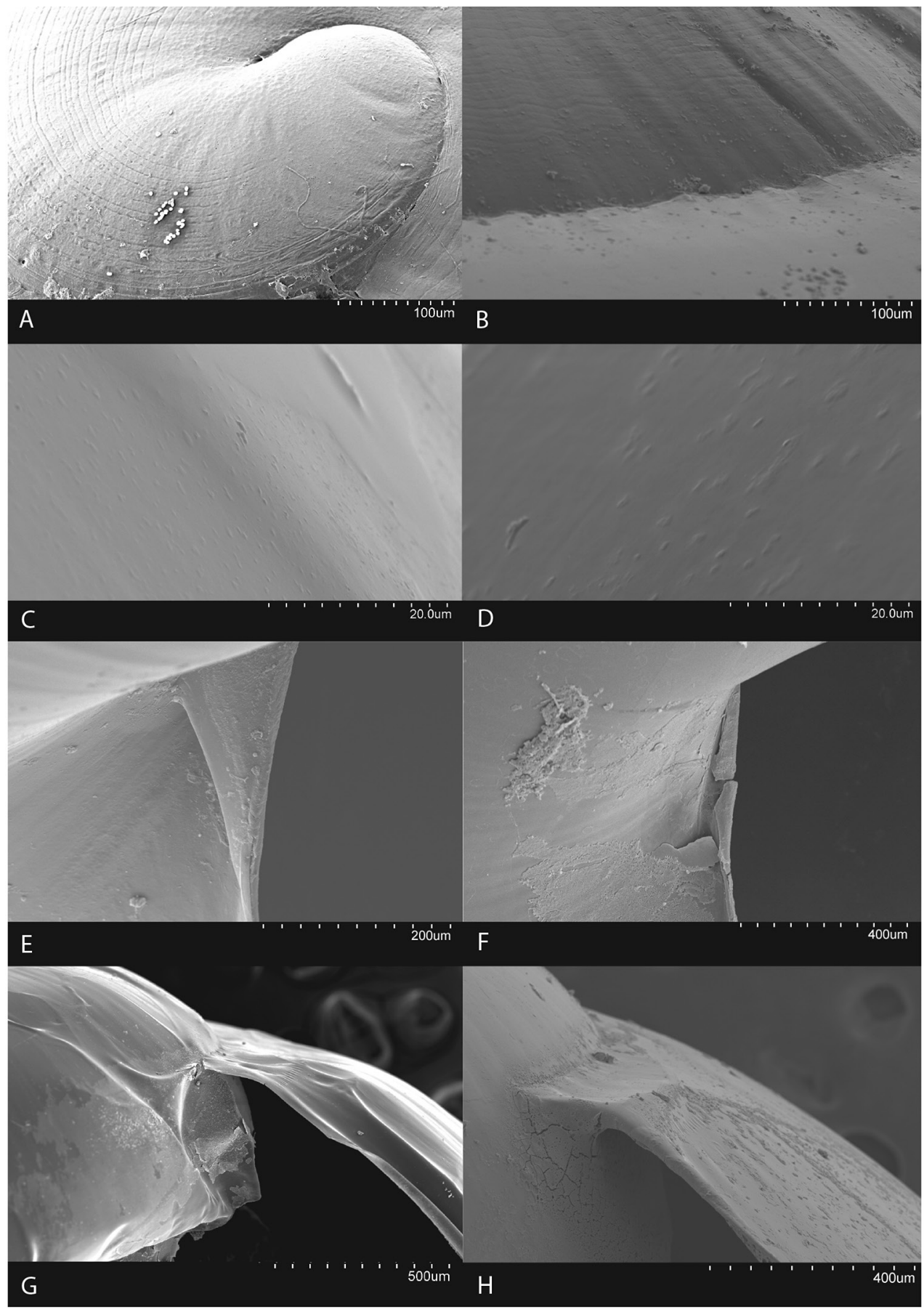

Fig. 6. Shell characteristics of the genus Tikoconus. A: embryonic sculpture, B: body whorl suture, C-D: variation in body whorl micro sculpture, E-F: variation of umbilicus shape, G-H: variation in outer shell lip thickness. 
is not a good character for species identification: there is much variation within a single species. Additionally, growth is not determinate and therefore fully-grown specimens are difficult to identify. Differences in shell size are the result of measuring snails of various ages and do not reflect a specific characteristic of the species.

External anatomy (Fig. 3): Cephalopodium evenly broad, quite long posteriorly, cannot be completely withdrawn into the shell. Sole tripartite, white. Aulacopod pedal grooves. Cephalopodium background colour white, colour pattern distinctive for different species. Subpedal groove band always pigmented, although sometimes only with few gray to black blotches. Caudal pore and horn present. Caudal pore white, T-shaped. Caudal pore white, T-shaped. Caudal horn dorsal and lateral surfaces gray, base light gray; size and shape of horn varies from imperceptible to large and projecting, according to snail's activity. Anterior lateral foot area under the shell white. Head colour has white background with overlaying black to dark gray squares matching epidermis texture; pigmentation is lacking on a small area above suprapedal groove line; median groove with a slender gray line, bordered on both sides by a parallel white band and another black to gray line. Tentacle colour only visible in live specimens, when they are not retracted. Base of optical tentacles with interrupted gray lines, a continuation of the head's dorsomedial lines; tips are uniformly dark gray. Labial tentacles are uniformly medium gray. Mantle collar expanded to the front, divided into two white lobes which cover part of the head. Right mantle lobe starting at the pneumostome and covering a small part of the right side of the head. Left mantle lobe also starting at the pneumostome slightly overlapping right mantle lobe, and covering a small part of head's dorsum and left side. Mantle collar expanded backwards with two fused shell lappets. Shell lappet pigmentation varies between species, although background is always white. Right shell lappet large, covers part of the body whorl, umbilicus, and shell base, and reaches embryonic whorls but does not surround body whorl. Left shell lappet narrow, margin waveshaped, covering the peristome and part of the body whorl but leaving urethra projection visible through transparent shell. Mantle colour pattern visible through the transparent shell. Mantle background white, with one black lineshaped blotch along the kidney's base reaching albumen gland, and one irregular blotch above urethra projection. Mantle never with tiny well defined black dots spread randomly. In life, mantle, mantle collar and cephalopodium more yellowish; odontophore reddish. The colour pattern of the cephalopodium and shell lappets are consistent within each species and can be used for species identification.

Mantle cavity organs (Fig. 4): Triangular kidney. Secondary urethra complete. Urethra with an S-shaped projection if seen from the inside, Z-shaped projection if seen from the outside. Urethra projection almost reaches mantle edge. The urethra projection is characteristic of the genus, but not exclusive, as another undescribed euconulid semislug genus has a similar projection (Barrientos, unpublished). Primary urethra not glandular, entering middle urethra by a simple pore. Middle urethra glandular, surrounding primary urethra's tip. Transition between middle and secondary urethra marked by a gradual loss of glandular tissue. Secondary urethra not glandular. Heart adjacent to kidney, between 1.0 and 1.75 times kidney's length; auricle well developed; ventricle variable in shape and development, but mostly rectangular, less developed and narrower than auricle but about same length. Pulmonary vein very short, sometimes absent, not branched, fused to primary urethra's basal half. Although the characteristics of the mantle cavity are consistent and useful for the identification of the genus, they vary widely within a species and thus cannot be used for species identification.

Reproductive system (Fig. 5): Atrium large, slightly twisted, ring muscles sometimes rudimentary, with or without accessory bulges 
on male and female side according with the subgenus. Penis small, sturdy with an external C-shaped penial gland well developed, surrounding about the half of the penis width and covering more than half penis length. Penial gland's inner and outer ends spherical and protruding, outer end better developed, middle part well-developed. Penial gland tightly attached to penial wall, without ducts, and visible through the penis' inside when dissected. Penis internally with a small, conic verge with a longitudinal duct inside that ends in a pore. Upper part of the penial wall forms a prepuce sometimes with a prepuce valve beneath the verge's tip; prepuce short, slightly longer than verge, thin, surrounds verge tightly, with transverse internal pilasters; end near verge's tip sometimes thickened forming a valve. Middle part of the penial wall non-differentiated or with internal pads. Lower part of the penial wall with a penis caecum, sometimes with penial pads and an internal extension of the penial gland, that can be mono- or bilobuled, sometimes it appears to be non-glandular. Location, amount, appearance and shape of internal glands and pads vary between species. Penis caecum medium size, conic, placed to one side, almost above of, attached to and partially wrapped by the penial gland outer end, there are no ducts between them, and it opens into the penis lower part. Velum lance like, white, thin, covers penial sheath base, penial gland, penis caecum, atrium and partially covers the vagina, fused with penial sheath, sometimes not present. Penis retractor short, originates on diaphragm, lies on uterus and attaches to epiphallus' base. Penis sheath surrounds penis upper part above the penial gland, epiphallus' base and penis retractor muscle insertion, but leaves penis' middle and lower part free; firm and muscular where it surrounds the epiphallus' base; soft and thin above penial gland. Gametolytic gland absent. Epiphallus elongated, oval-, bean- or U-shaped, wall thin and transparent, without flagellum, about same length and width as penis, subapically connected to vas deferens by a simple pore, inside with six or seven longitudinal, slender, slightly twisted pilsters a little corrugated near verge, one of the internal pilasters becomes the verge internal duct. Vas deferens slender, short, entering prostate's base, attached to penis base by a thread-like part of the velum that goes from one side of atrium to vagina or penis. Vagina subtriangular. Perivaginal gland well developed but thin, completely surrounding the vagina, placed in basal position near atrium. Free oviduct same size as vagina. Uterus large and well developed. Prostate band shaped, adnate to uterus, short, about half the uterus length. Talon clavate or digitiform, small or small, exposed to slightly exposed. Carrefour sausage shaped, much bigger than talon, thick-walled, small tubercules on inner wall. Right ocular tentacle muscle retractor runs between male and female reproductive tract, attached to columellar wall. Hermaphroditic duct coiled, broader in the middle, tapering at each end. Ovotestis with three clusters consisting of few acini. The development of the penial gland and the internal characteristics of the penis are consistent within each species, including verge, prepuce, prepuce valve, internal penial gland and pads, and caecum: much attention should be paid to these characters.

Dentition: Jaw almost smooth, with a small to large protruding tooth on the frontal side and a median ridge along the longitudinal midline. Median ridge may reinforce the jaw attachment; its surface is sculptured with pentagonal or hexagonal polygons. Jaw shape in cutting edge view convex or angulated according to the subgenus. Central teeth of radula symmetric, tricuspid, base slightly narrower, mesocone lancelolate but slender, one lanceolate ectocone on each side, shorter than mesocone and slightly narrower. Lateral teeth asymmetric tricuspid; base slightly wider than central teeth's base also slightly asymmetric; mesocone large, ectocone large but smaller than mesocone; endocone small. Primary marginal teeth bicuspid. Last marginal teeth generally bicuspid, but some are mono- or have a serrated ectocone. When alive the reddish 
odontophore is visible through the epidermis of the head (except in T. andresi).

Habitat, behaviour and ecological notes: Members of this genus live mainly in primary forests; sometimes in secondary forests with a well-developed canopy. They are understory tree dwellers and spend most of their time on and under shrub leaves and on moss growing on branches, in very wet and rainy forest. Their colour pattern camouflages them in moss. They normally eat microalgae that grow on leaves, but some species may occasionally eat moss, fungi or dead arthropods. Specimens are often found on leaves of trees and shrubs in the families Piperaceae (pepper family), Melastomataceae (some species are known as silver leaf princess flower), Cyclanthaceae (known as the Panama hat plant family), Arecaceae (locally known as palmito) and Araceae (known as aroids). They have several reactions to negative conditions: move the tail vigorously and even throw themselves from leaves into leaf litter when disturbed (a possible reaction to parasitoids or predators), or in reaction to strong sunlight; or hang from under leaves when the air is very dry or windy. This is done by attaching the caudal horn or distal part of the foot with mucus produced by their caudal pore. Usually they enter aestivation when they hang. No epiphragm is produced. They groom themselves with the radula, possibly to eliminate fungi and other potential pathogens; additionally, they use the radula to clean the caudal pore of hardened mucus or to break the mucus thread used for hanging from the leaves.

Distribution: The genus Tikoconus lives in Costa Rica's mountain ranges from 400 to 2500 masl on the Caribbean slope and from 760 to 2500 masl on the Pacific slope. It does not occur in lowlands. The group's northern limit is the south end of the Guanacaste mountain range, but its southern limit is unknown. They are not known to reach the Panama Canal.

Etymology: The genus name Tikoconus is formed from the words "Ti" from Huetar, an already extinct language that was spoken in Costa Rica`s mainland, meaning water; "Kö'" that means leaf in Cabecar, another native language; and "conus" from the latin word for cone, often used in gastropod taxonomy. Therefore, the genus name is given due to their occurrence on understory leaves of very wet habitats.

\section{Tikoconus subg. nov.}

Type species: Tikoconus (Tikoconus) costaricanus, n.sp.

Diagnosis: The subgenus Tikoconus can be identified by its slug-like appearance; subglobose-depressed and very thin shell (between 2 and $5.5 \mu \mathrm{m}$ thick), that is flexible when the snail is alive; small to medium-size protruding tooth on jaw; jaw middle area not differentiated from lateral arms by a deep wrinkle; jaw convex in cutting edge view; middle part of the penis not differentiated and atrium with bulges on both sides.

Etymology: Same as genus etymology.

\section{Tikoconus (Tikoconus) costaricanus n.sp.}

Diagnosis: Lateral foot band pigmented from suprapedal groove line to dorsomedial groove, colouration missing under the shell; subpedal groove band and suprapedal groove line interrupted forming rectangles, better defined near the posterior end; sole white; mantle translucent, usually with two gray irregular blotches above the urethra's projection; shell lappets without special pigmentation; penis with a bi-lobulated internal penial gland; prepuce with a valve; verge curved.

Shell (Fig. 7, Fig. 8, Digital Appendix 1: Fig. 1, Fig. 2, Fig. 3, Fig. 4, Fig. 5, Table 1): As in the genus with the following exceptions. Subglobose depressed, yellowish-green, very thin (approximately $3.6 \mu \mathrm{m}$ ), fragile, flexible when alive. When alive the shell is more yellowish. Holotype whorls 3.25 , height $3.5 \mathrm{~mm}$, 


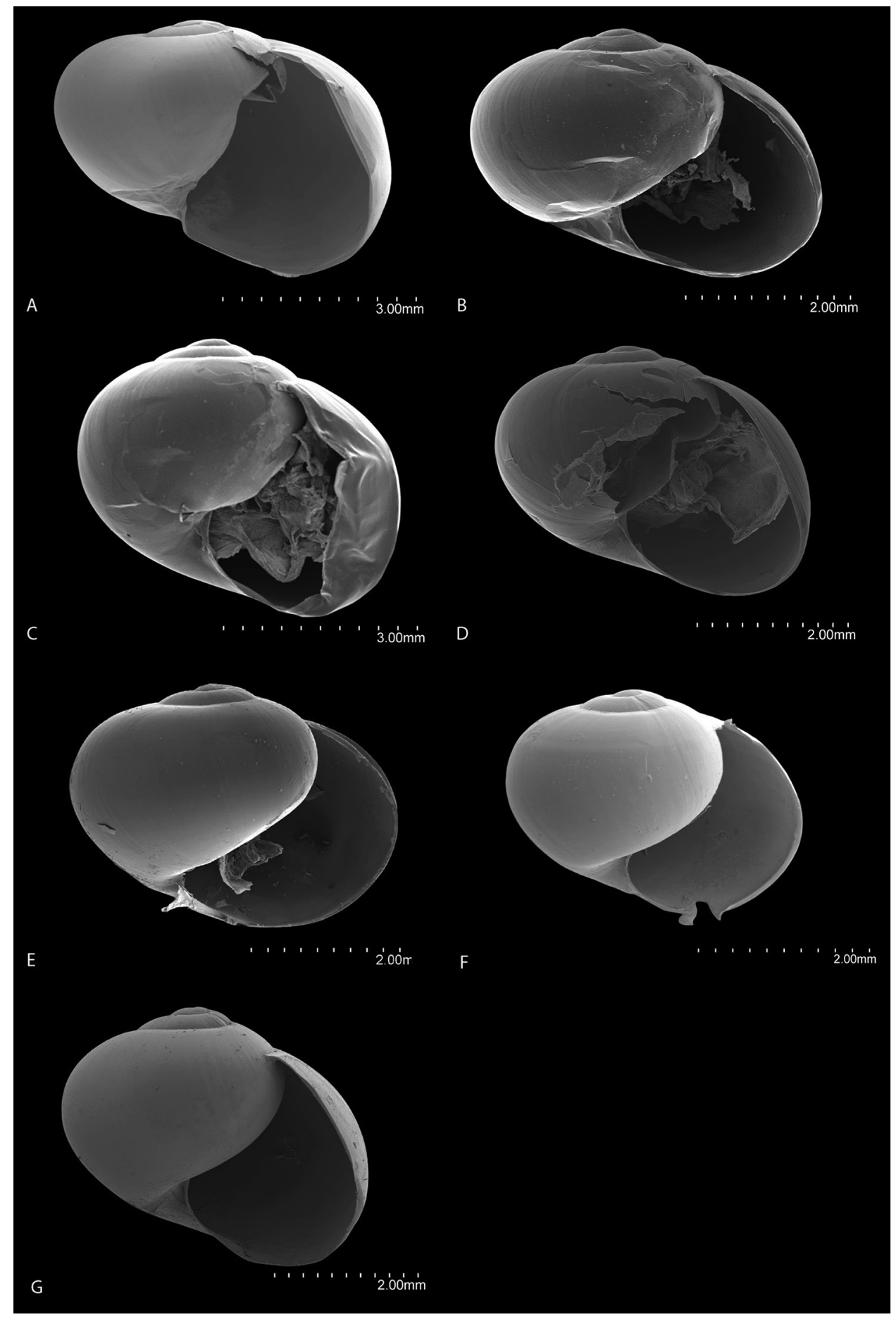

Fig. 7. Frontal view of the shells of Tikoconus spp. A: T. costaricanus, B: T. onca, C: T. andresi, D: T. katyae, E: T. alosii, F: T. subsilvanus, G: T. thompsoni. 


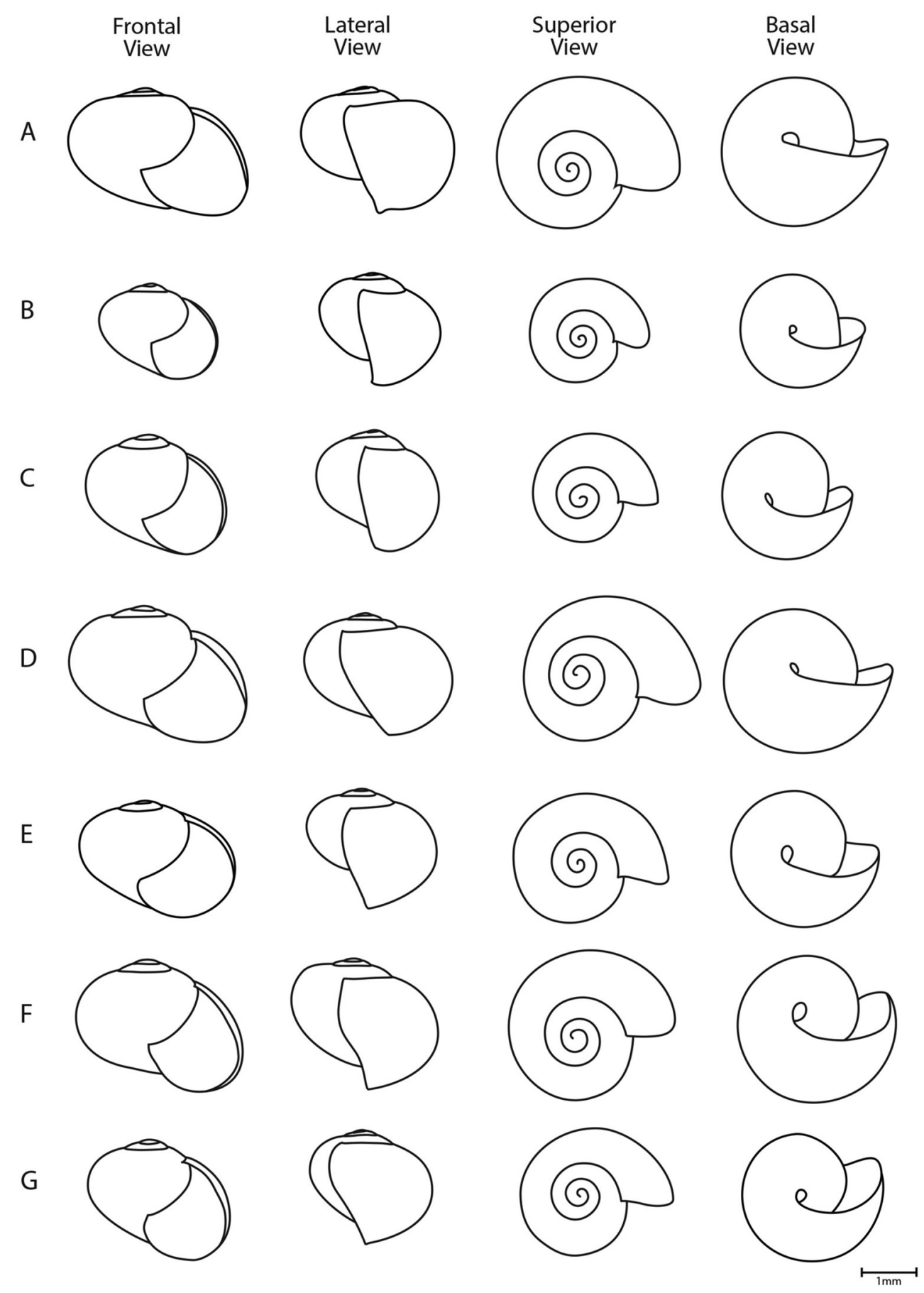

Fig. 8. Diagrams of the shell of Tikoconus spp. in frontal, lateral, superior and basal view. A: T. costaricanus, B: T. onca, C: T. andresi, D: T. katyae, E: T. alosii, F: T. subsilvanus, G: T. thompsoni. 


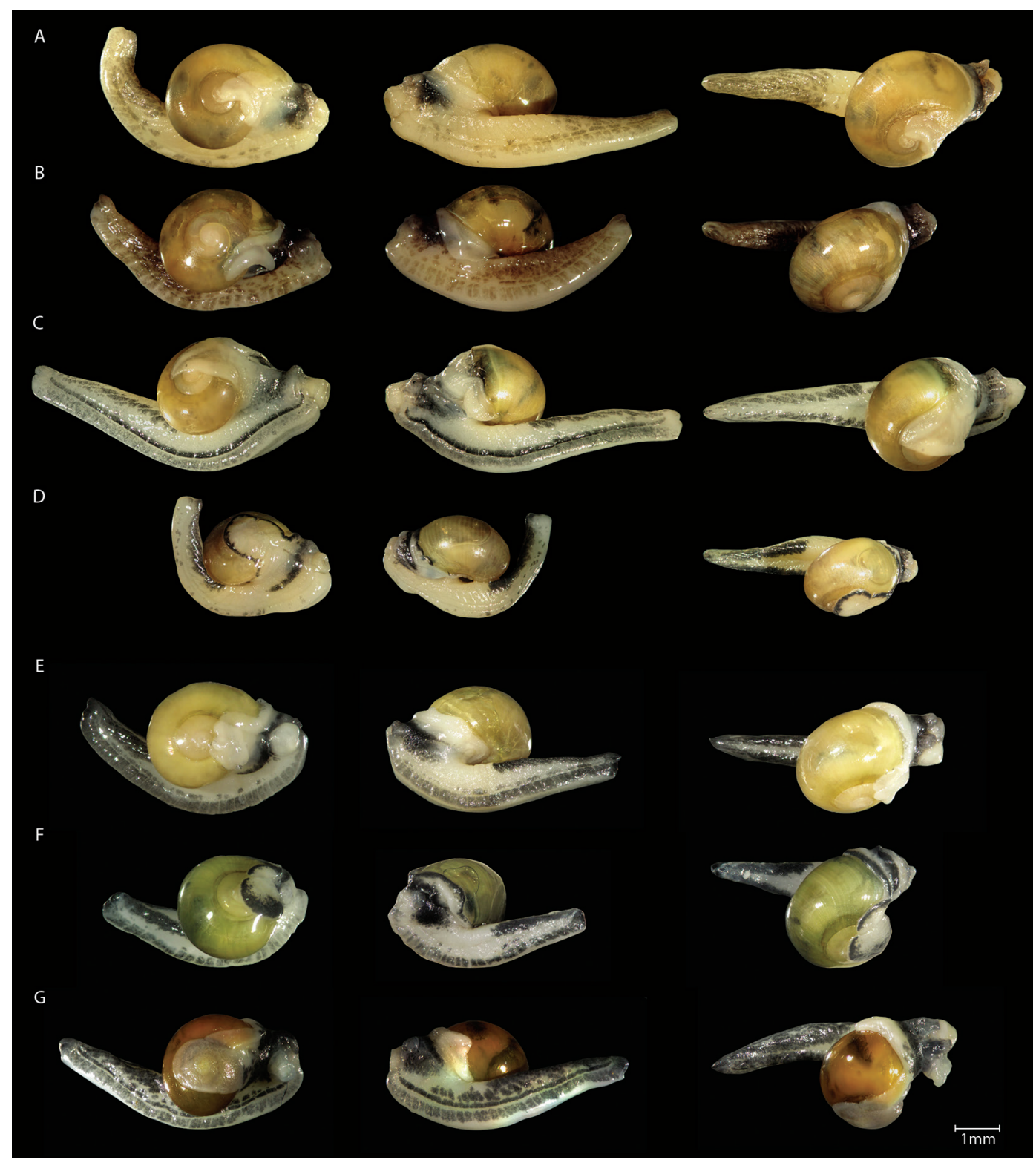

Fig. 9. Holotypes of Tikoconus spp. A: T. costaricanus, B: T. onca, C: T. andresi, D: T. katyae, E: T. alosii, F: T. subsilvanus, G: T. thompsoni.

width $5.1 \mathrm{~mm}$, apex $0.5 \mathrm{~mm}$, transition from protoconch to teleoconch not well defined.

External anatomy: I examined a total of 895 specimens (Fig. 9, Fig. 10, Digital Appendix 1: Fig. 6, Fig. 7, Fig. 8, Fig. 9, Table 2): As described for the genus. Holotype cephalopodium width $1.9 \mathrm{~mm}$, length $11.2 \mathrm{~mm}$. Subpedal groove band colour pattern composed of light gray rectangles that are higher than wide, upper part of each rectangle shifted anteriorly, well defined near the caudal horn but not extending to the head, epidermal grooves are white and ridges gray. Suprapedal groove 

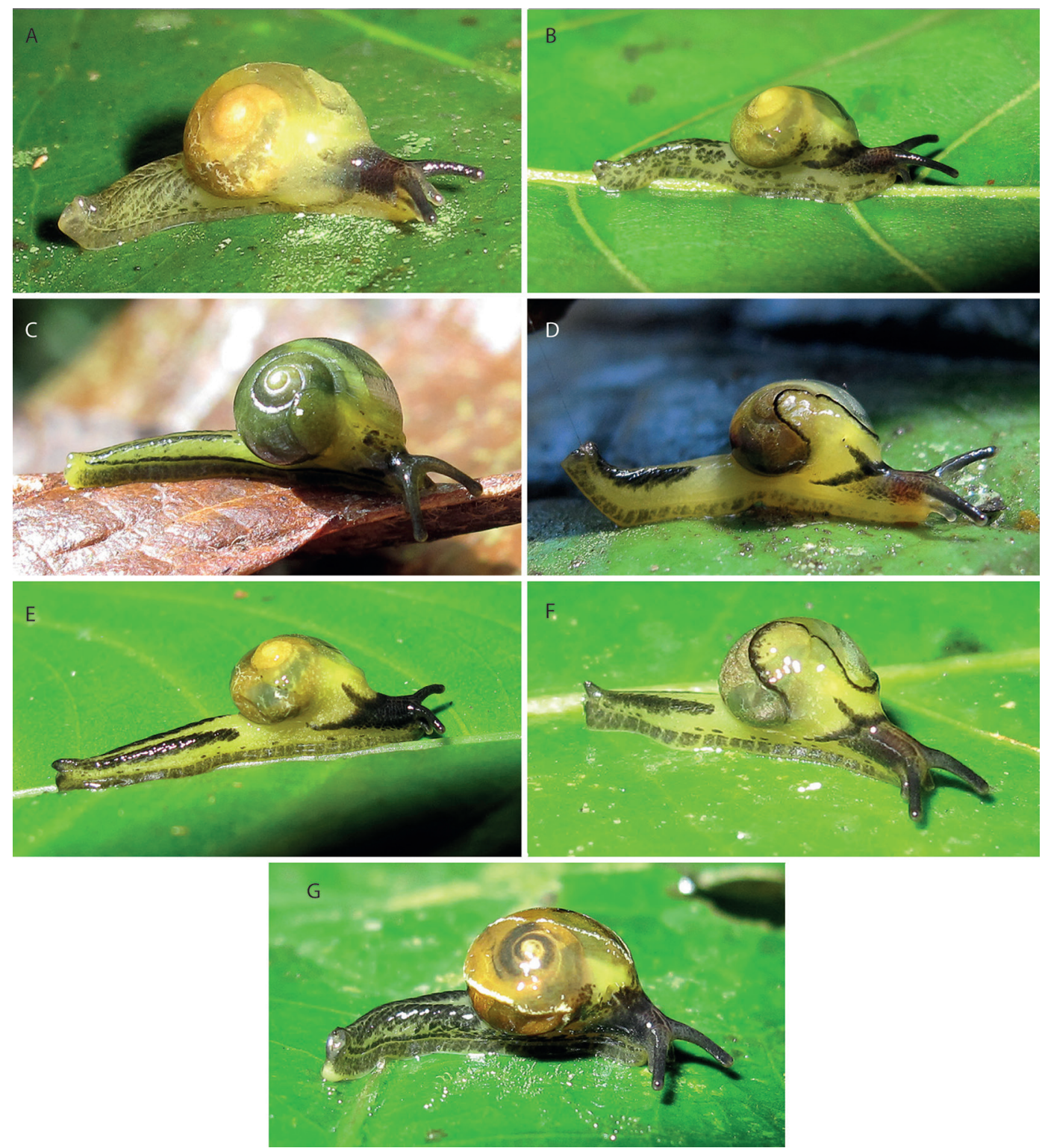

Fig. 10. Right side color pattern of living Tikoconus spp. A: T. costaricanus. B: T. onca. C: T. andresi. D: T. katyae. E: T. alosii. F: T. subsilvanus. G: T. thompsoni.

line colour light gray broken into dashes, better defined and darker near the caudal end, almost absent near the head and middle part of the foot. Posterior lateral foot area colour matches epidermis texture, with background and grooves white, ridges light gray forming oblique light gray bands with their upper part shifted anteriorly; these gray bands start slightly above suprapedal line and reach the dorsomedial groove. Dorsomedial groove not well defined, thin, white, extending back to caudal horn. Right mantle lobe with a diffuse gray band darkening at the margin. Left mantle lobe colouration diffuse gray, darkening at the margin above the dorsal surface of the head; the left side is white. Right shell lappet fan-shaped, 


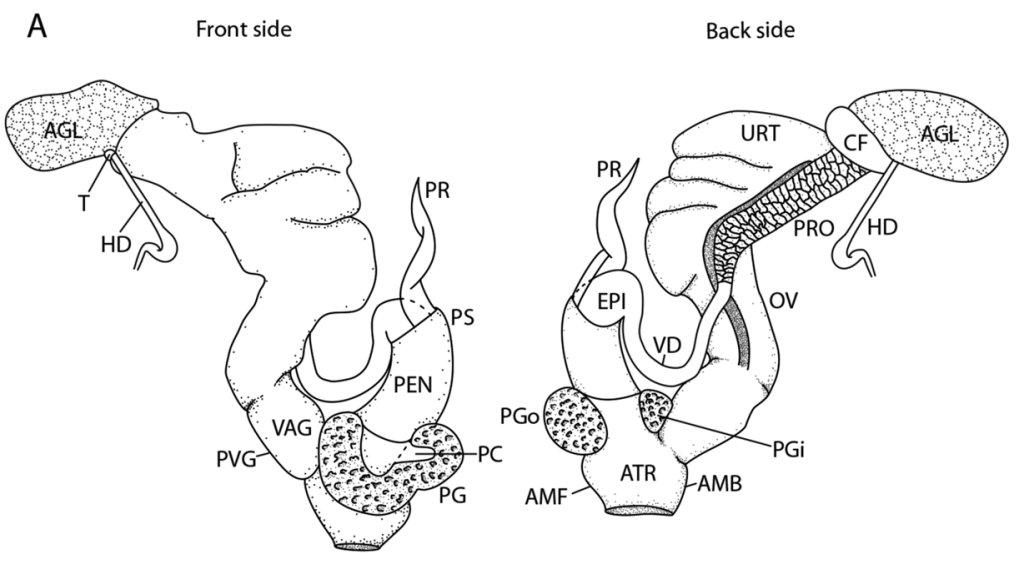

B
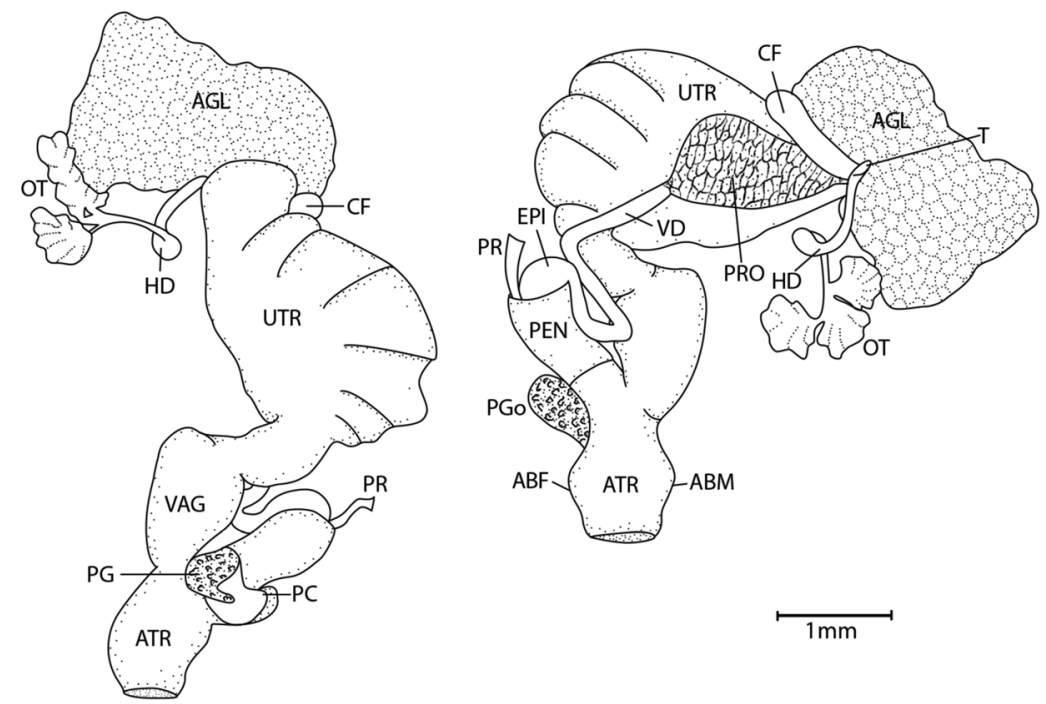

Fig. 11. Reproductive system of Tikoconus spp. A: T. costaricanus, B: T. onca. Velum, velum thread and, in some cases, ovotestis are not illustrated. For abbreviations see Fig. 5. 
C Front side

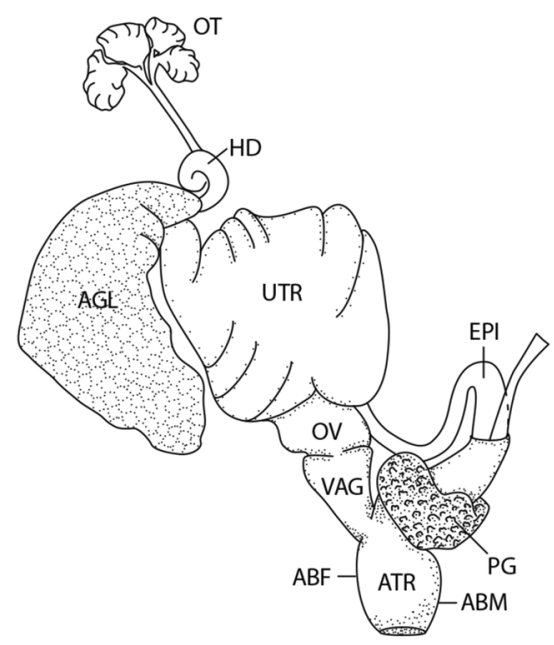

D

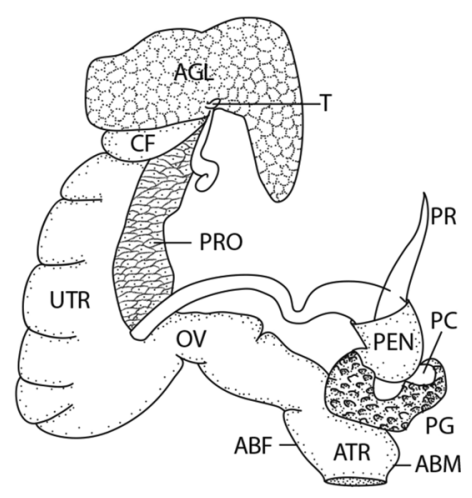

Back side
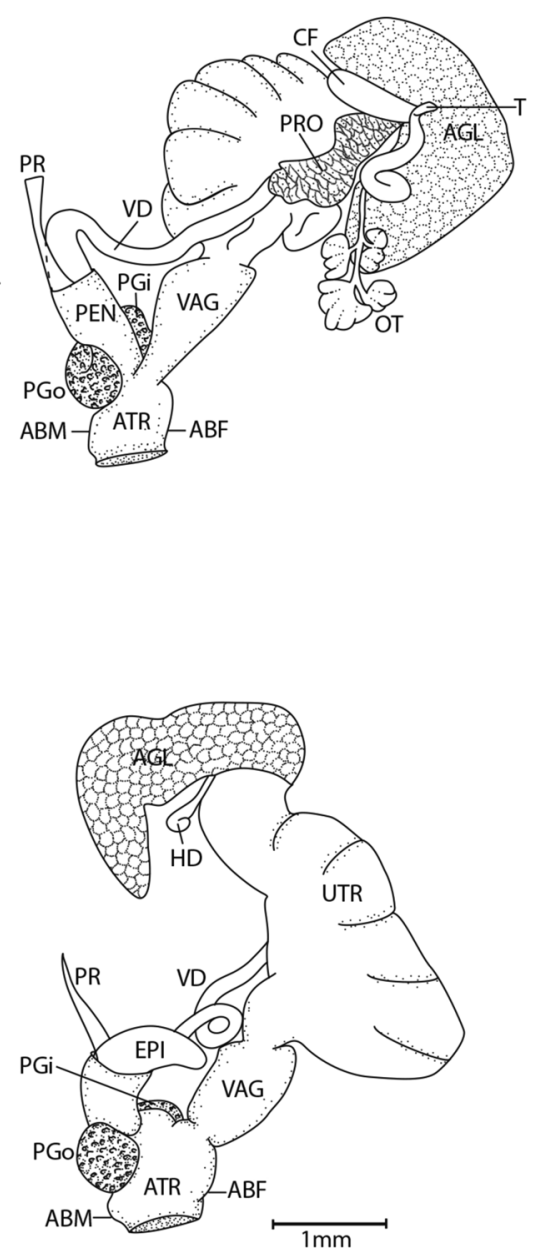

Fig. 11. Reproductive system of Tikoconus spp. C: T. andresi. D: T. katyae. Velum, velum thread and, in some cases, ovotestis are not illustrated. For abbreviations see Fig. 5. 

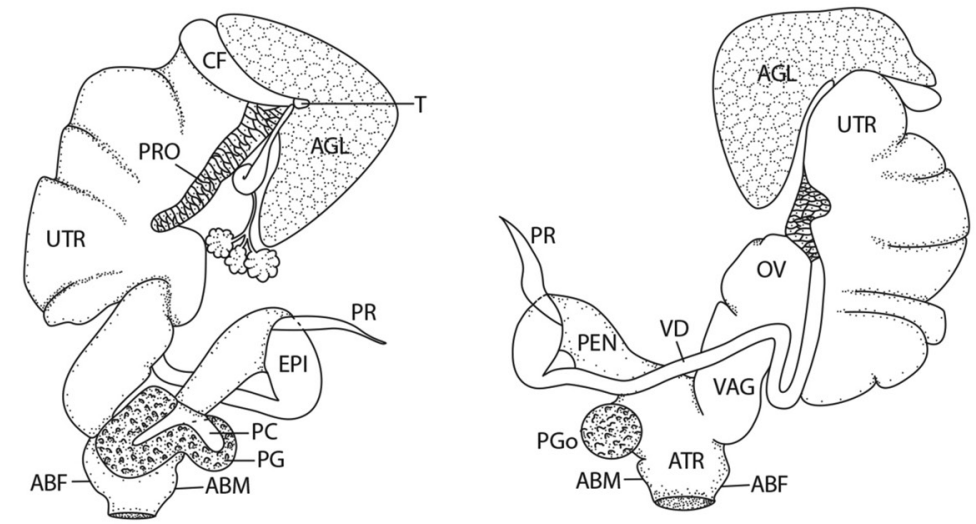

F
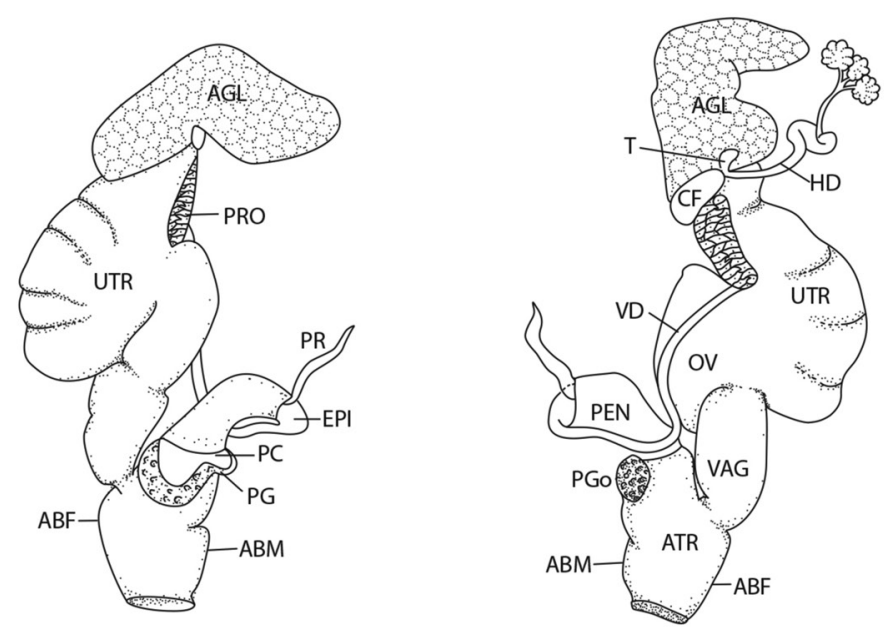

$1 \mathrm{~mm}$

Fig. 11. Reproductive system of Tikoconus spp. E: T. alosii. F: T. subsilvanus. Velum, velum thread and, in some cases, ovotestis are not illustrated. For abbreviations see Fig. 5. 
Front side

G

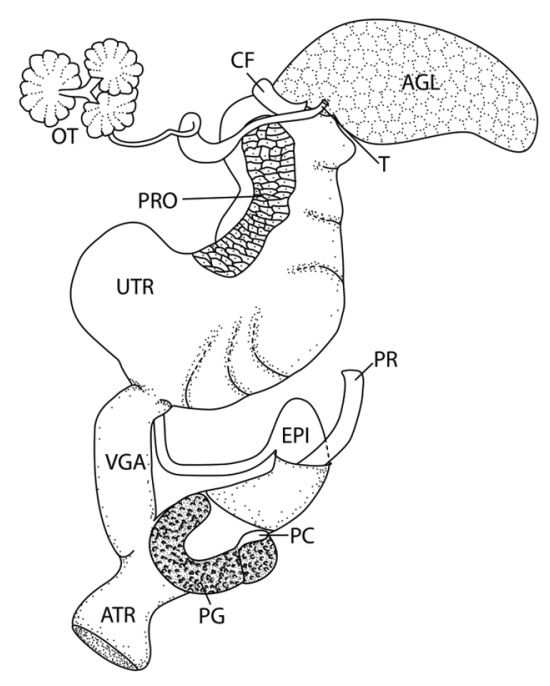

Back side

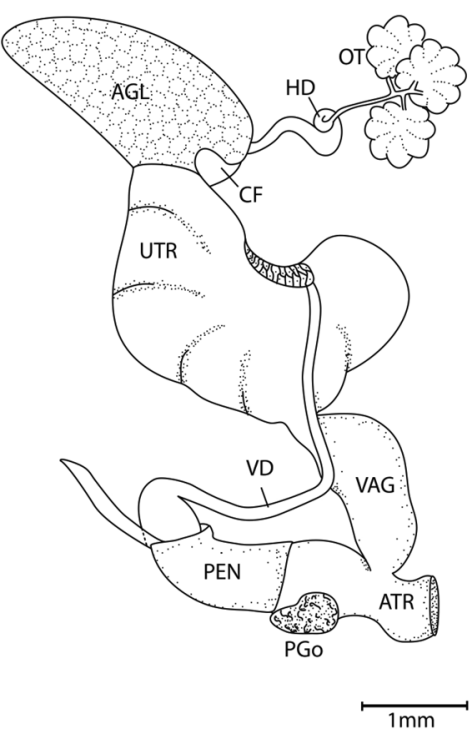

Fig. 11. Reproductive system of Tikoconus spp. G: T. thompsoni. Velum, velum thread and, in some cases, ovotestis are not illustrated. For abbreviations see Fig. 5.

sprinkled with black in some paratypes. Left shell lappet overlain with small black flecks in some paratypes. Mantle usually with two gray irregular blotches above the urethra projection (although some paratypes have only one or no blotches), usually without a linear blotch at kidney's base.

Mantle cavity organs (Digital Appendix 1: Fig. 10, Table 3): As described for the genus.

Reproductive system (Fig. 11, Fig. 12, Digital Appendix 1: Fig. 11, Fig. 12, Fig. 13, Table 4): As in the genus and subgenus except for the following differences. Atrium sculptured with 10 internal ring folds parallel to atrium width. Internal penial gland bilobuled, in some specimens it does not seem glandular, main and secondary lobules pillow-shaped, secondary lobule placed to one side of the main lobule. Without penial pads. Verge with one side slightly curved near the base, with a subapical pore. Prepuce with three or four narrow transverse pilasters surrounding verge; prepuce valve present. Penis caecum very small. Velum loose. Epiphallus oval shaped, bent at both ends. Vas deferens attached from one side of atrium to the other by a thread-like part of velum. Uterus with a broad gray duct running adjacent to the prostate and along uterus and free oviduct. Talon very small, digitiform, slightly exposed. Carrefour bag-shaped.

Dentition (Fig. 13, Digital Appendix 1: Fig. 14, Fig. 15, Fig. 16): Jaw as in the subgenus. Dentition formula: 32-15-1-15-32. Teeth as in the genus.

Type locality: Costa Rica, Cartago, Orosi, Reserva Forestal Río Macho, at "El llano" water dam. 1600 masl. $09^{\circ} 45^{\prime} 56.07^{\prime \prime} \mathrm{N} \&$ 8351'47.11" W.

Holotype: MZUCR-232-10. Collected on 22 March 2011 by Z. Barrientos and M. Zúñiga. (T.: ZB-232).

Paratypes (Total of 57 paratypes designated and examined): MZUCR-232-01 (1 dissected specimen), MZUCR-232-02 (1 dissected specimen), MZUCR-232-03 (1 dissected specimen), MZUCR-232-04 (1 dissected 

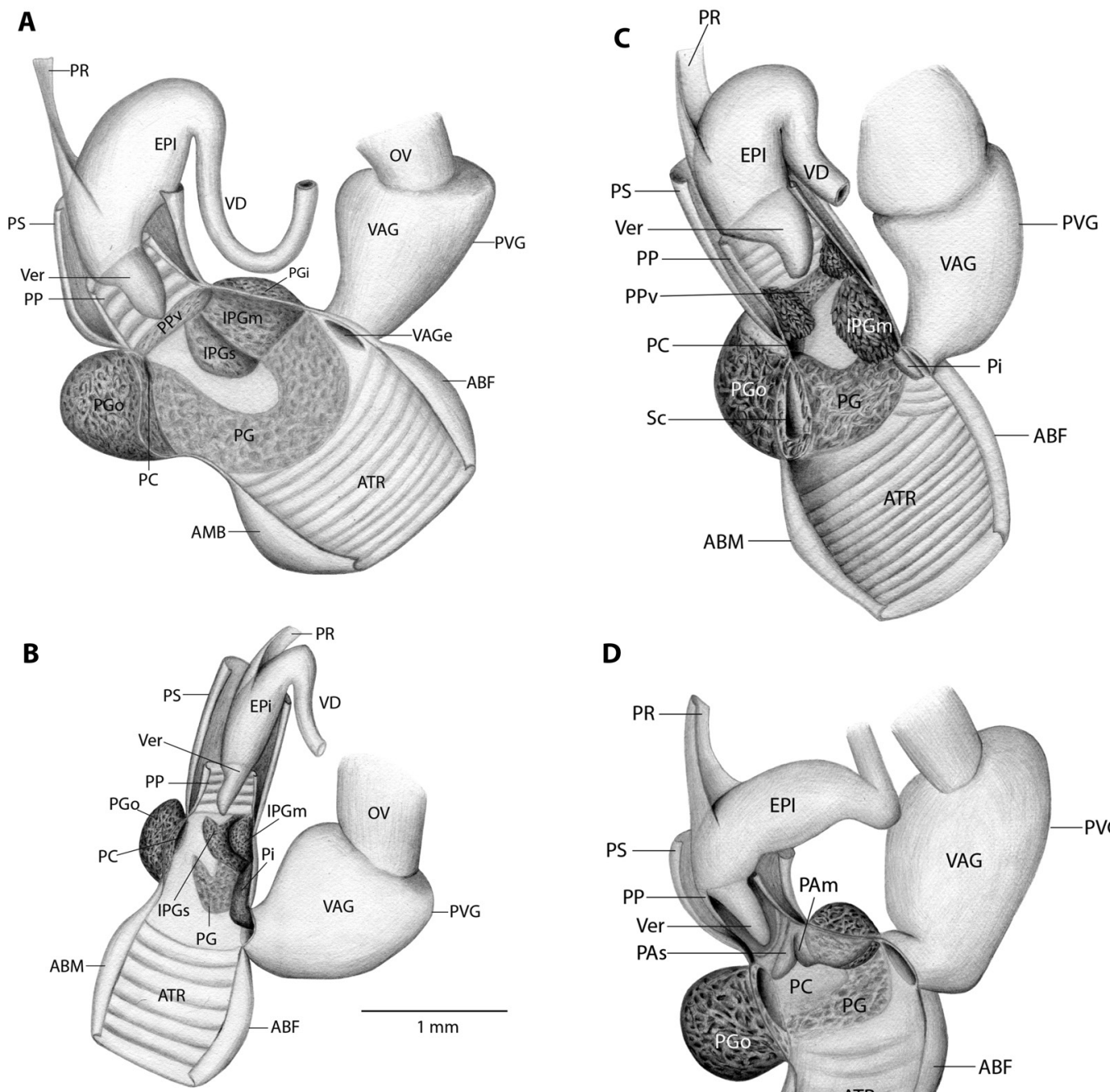

Fig. 12. Penis dissection of Tikoconus spp. A: $T$. costaricanus. B: T. onca. For abbreviations see Fig. 5.

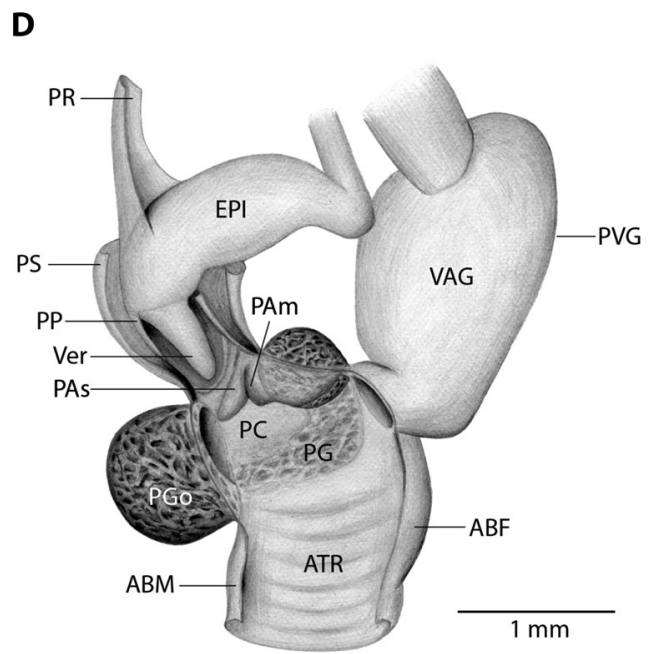

Fig. 12. Penis dissection of Tikoconus spp. C: T. andresi. D: T. katyae. For abbreviations see Fig. 5. 

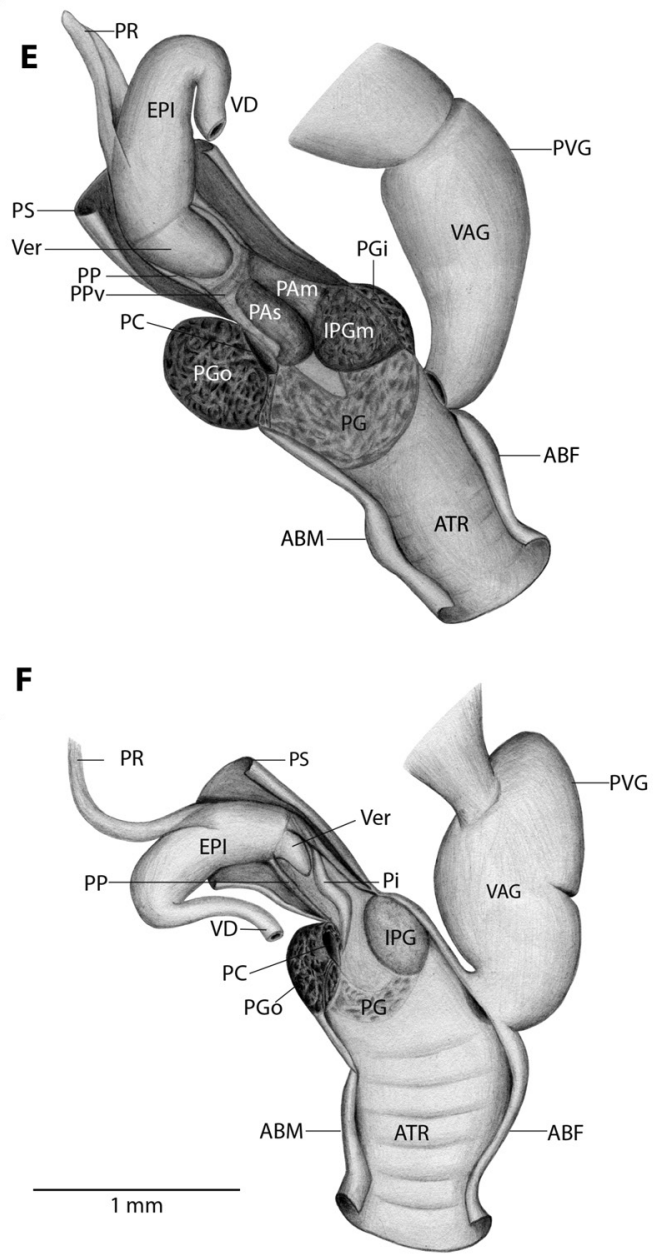

Fig. 12. Penis dissection of Tikoconus spp. E: T. alosii. F: T. subsilvanus. For abbreviations see Fig. 5.

specimen), MZUCR-232-05 (1 dissected specimen), MZUCR-232-06 (1 dissected specimen), MZUCR-232-07 (1 dissected specimen), MZUCR-232-08, (1 dissected specimen), MZUCR-232-09 (1 dissected specimen), MZUCR-232-11 (2 specimen) same data as holotype.

MZUCR-242-01 (9 specimens). Costa Rica, Cartago, Orosi, Reserva Forestal Río Macho, at "El llano" water dam. 1600 masl. 0945'56.07" N \& 83 51'47.11" W. Collected on 5 March 2012 by Z. Barrientos, M. Zúñiga and A. Induni. (T.: ZB-251).

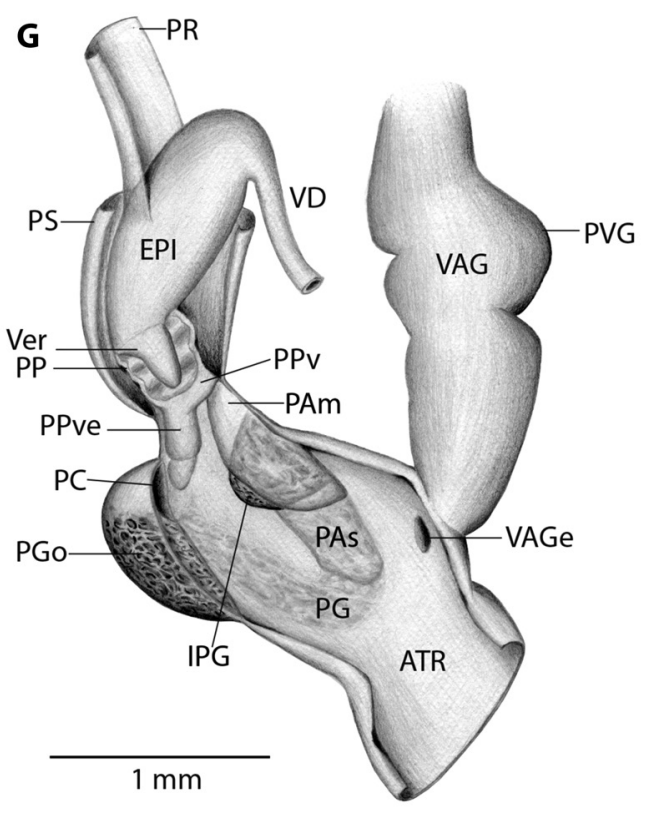

Fig. 12. Penis dissection of Tikoconus spp. G: T. thompsoni. For abbreviations see Fig. 5.

MZUCR-256-01 (1 dissected specimen), MZUCR-256-02 (1 dissected specimen), MZUCR-256-04 (7 specimens), MZUCR-25605 (1 dissected specimen), MZUCR-256-06 (1 dissected specimen), MZUCR-256-07 (1 dissected specimen), MZUCR-256-08 (1 dissected specimen), MZUCR-256-09 (1 dissected specimen), MZUCR-256-10 (1 dissected specimen). Costa Rica, Cartago, Orosi, Reserva Forestal Río Macho, at "El llano" water dam. 1 600 masl. 0945'56.07" N \& 8351'47.11" W. Collected on 6 December 2011 by Z. Barrientos and M. Zúñiga. (T.: ZB-238).

MZUCR-259-02 (5 dissected specimens). MZUCR-259-03 (1 dissected specimen). Costa Rica, Cartago, Orosi, Reserva Forestal Río Macho, at "El llano" water dam. 1600 masl. 0945'56.07" N \& 8351'47.11” W. Collected on 1 October 2012 by Z. Barrientos and M. Zúñiga (T.: ZB-261).

MZUCR-218-04 (1 dissected specimen). Costa Rica, Cartago, Orosi, Reserva Forestal Río Macho, at "El llano" water dam. 1 600 masl. 0945'56.07" N \& 8351'47.11” W. 


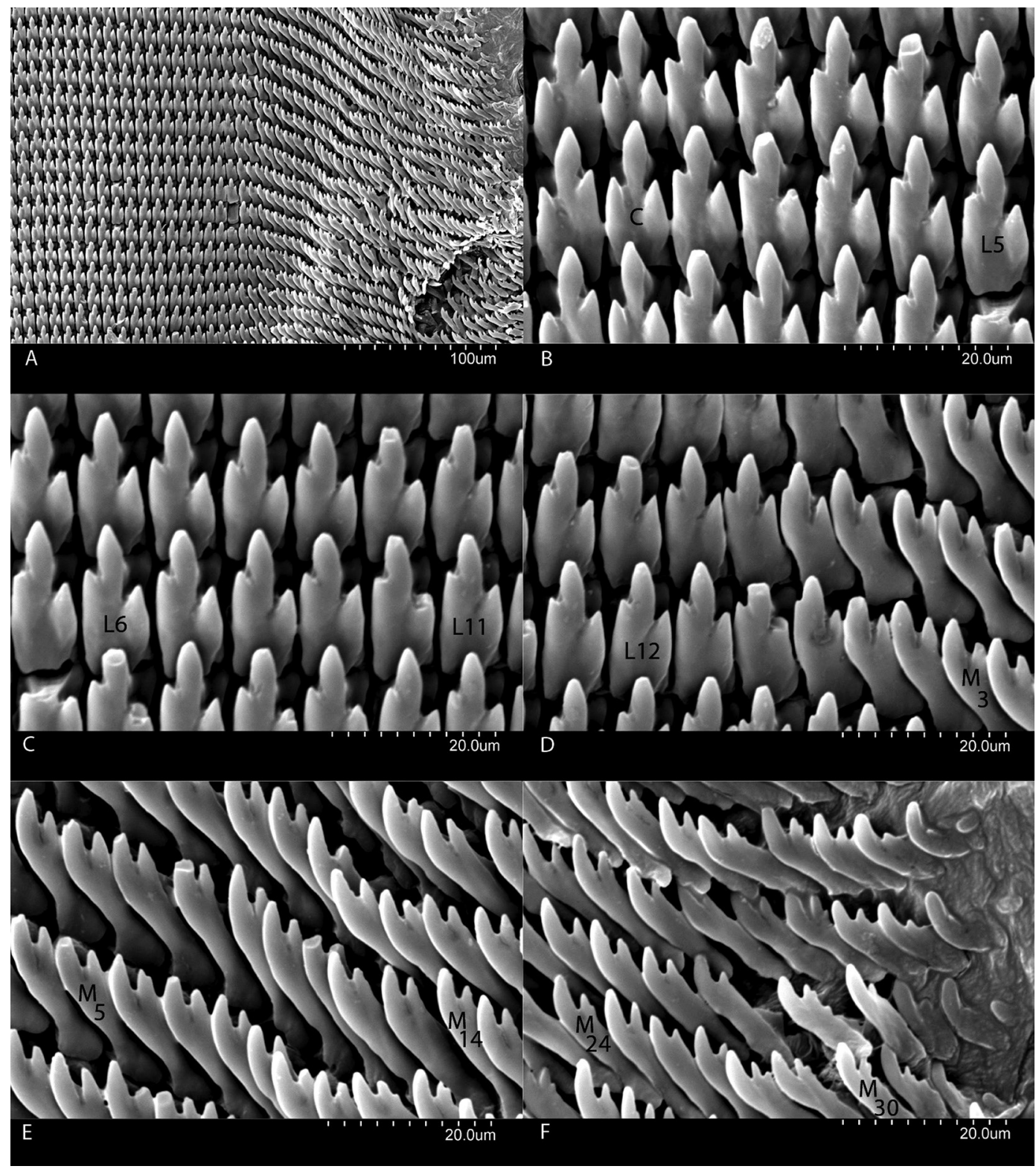

Fig. 13. Radula of Tikoconus costaricanus. A: Right side general view. B: Central (C) and lateral teeth (L1 to L5). C: Lateral teeth (L5 to L11). D: Lateral teeth (L11 to L15) and primary marginal teeth (M1 to M4). E: Marginal teeth (M4 to M 15). F: Marginal teeth (M24 to M32).

Collected on 25 March 2010 by Z. Barrientos and M. Zúñiga (T.: ZB-184).

UF-465682 (6 specimens). Costa Rica, Cartago, Orosi, Estación Río Macho, at "El llano" water dam. 1600 masl. 0945'56.07" $\mathrm{N} \& 83^{\circ} 51^{\prime} 47.11^{\prime}$ 'W. Collected on 1 October
2012 by Z. Barrientos and M. Zúñiga. (T.: ZB-261).

CNMO 4829 (6 specimens). Costa Rica, Cartago, Orosi, Estación Río Macho, at "El llano" water dam. 1600 masl. $09^{\circ} 45^{\prime} 56.07^{\prime \prime} \mathrm{N}$ 
\& 8351'47.11"W. Collected on 1 October 2012 by Z. Barrientos and M. Zúñiga. (T.: ZB-261).

ANSP-A477023 (3 specimens). Costa Rica, Cartago, Orosi, Reserva Forestal Río Macho, at "El llano" water dam. 1640 masl. 0945'56.07” N \& 83 51'47.11” W. Collected on 21 June 2011 by Z. Barrientos and M. Zúñiga (T.: ZB-255).

Habitat, behaviour and ecological notes: This species lives in mature and secondary forest in premontane, montane and cloudy tropical forests. They also occur in small numbers in cypress plantations. They can be abundant in some localities. They are understory dwellers and spend most of their time on and under leaves and on moss growing on branches. Sometimes they hide in leaf litter from unfavorable weather conditions. They eat epiphytes growing on leaves. This species can groom itself with the radula. They are also able to twist the cephalopodium strongly and rapidly when distressed, to escape from enemies. During dry and hot weather epiphragms are not produced. Instead, these snails hang from mucous threads by their mucus pore and the sole's caudal area. While hanging they keep their head and tentacles withdrawn in the shell. They are sympatric with T.andresi and T. subsilvanus and other euconulid snails and semislugs.

Remarks: Specimens throughout Costa Rica are very similar, having only small variations in colour pattern and penial gland size. Genetic studies are needed to determine if these variations indicate a possible species complex. This species is similar to T. onca in having a similar colour pattern on the foot and in lacking a white triangular area around the foot's dorsomedial groove. However, its blotches are rectangular and are not extended under the shell. This species is unique in having a welldefined subpedal groove band posteriorly that does not extend anteriorly. It is also the only species with a wide distribution. Although it is also similar to $T$. onca in its internal reproductive characteristics, the internal penial gland differs in shape and size.
Distribution (Fig. 14, Digital Appendix 2): This species occurs throughout the central Costa Rican mountain ranges, except the NW of the Guanacaste mountain range. Specimens occur from 760 to 2400 masl. Lowlands under 500 masl are probably the main geographic barrier for this species.

Etymology: Tikoconus costaricanus is named after its wide distribution in Costa Rica.

\section{Tikoconus (Tikoconus) onca n.sp.}

Diagnosis: Lateral foot band pigmented from suprapedal groove line to dorsomedial groove, colouration present under the shell; subpedal groove band and suprapedal groove line interrupted forming semi-round blotches, present from head to tail; sole white; mantle translucent, with one dark well-defined linear blotch above kidney's base, much darker and better defined than in other species; shell lappets without special pigmentation; penis with a bi-lobulated internal penial gland; prepuce without a valve; verge curved.

Shell (Fig. 7, Fig. 8, Digital Appendix 1: Fig. 1, Fig. 2, Fig. 3, Fig. 4, Fig. 5, Table 1): As in the subgenus and T. costaricanus, except that the color is light brown, thickness approximately $4.2 \mu \mathrm{m}$. Holotype whorls 3, height $3.6 \mathrm{~mm}$, width $5.1 \mathrm{~mm}$, apex $0.7 \mathrm{~mm}$, transition from protoconch to teleoconch not well defined. Aperture not descending in frontal view. When alive the shell is more greenish.

External anatomy: I examined a total of 49 specimens (Fig. 9, Fig. 10, Digital Appendix 1: Fig. 6, Fig. 7, Fig. 8, Fig. 9, Table 2): As in the description of the genus. Holotype cephalopodium width $1.5 \mathrm{~mm}$, length $11.3 \mathrm{~mm}$. Subpedal groove band colour pattern composed of dark to light brown subrectangles, sometimes almost spherical, higher than wide, upper part shifted anteriorly, well defined from head to caudal horn, lighter near the head, darker near the caudal horn, pigmentation does not fit so well with epidermal grooves. Suprapedal 


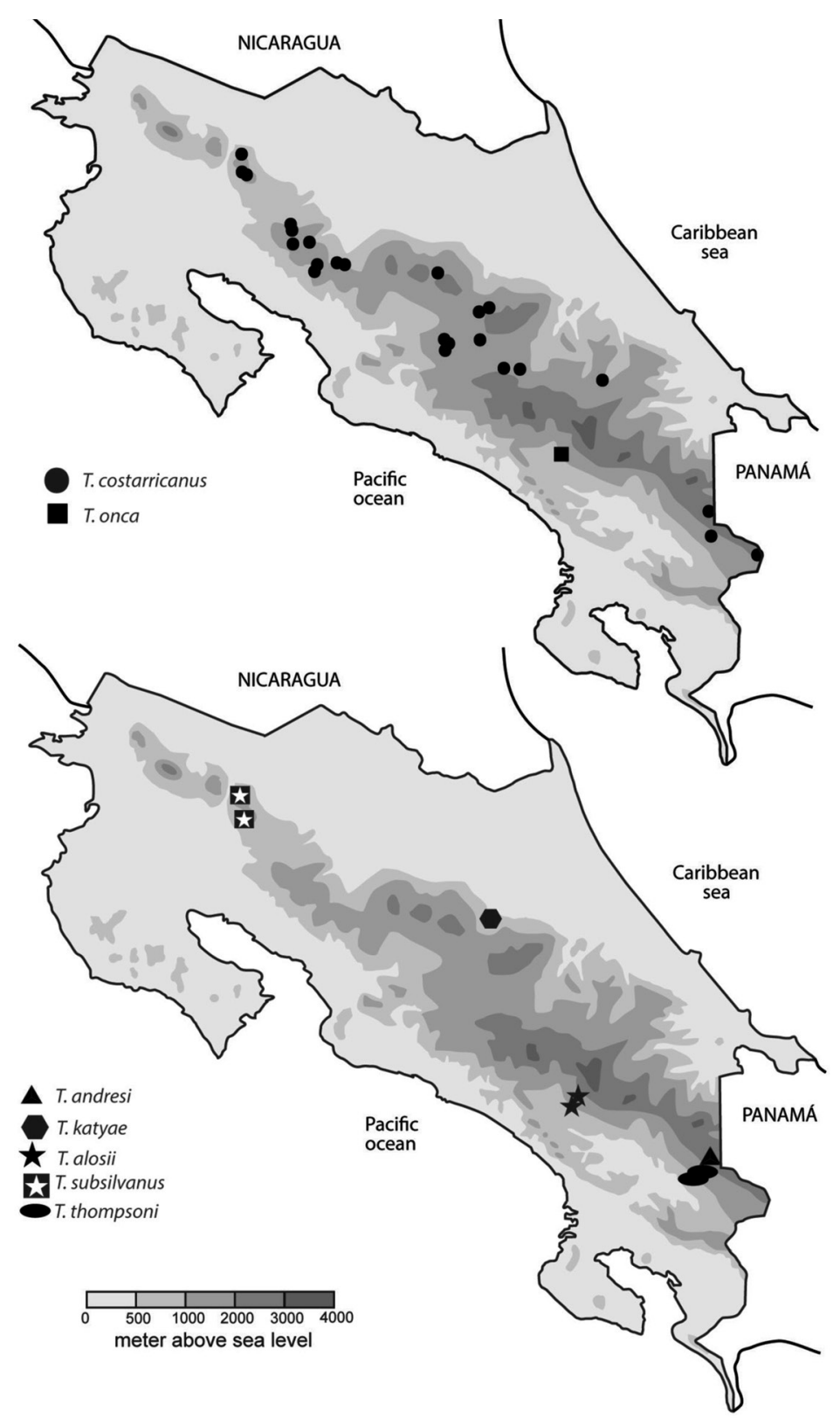

Fig. 14. Distribution of Tikoconus spp. in Costa Rica. Doubtful or erroneous collection sites are not included.

groove line medium to dark brown line broken into dashes, well defined from the head to the caudal horn, although dashes are lighter and sparser near the head. Posterior lateral foot area colour does not match epidermis texture, background white with overlaying medium to dark brown irregular spots, spots have darker and lighter randomly tinted areas giving a blotched appearance, and these spots start at suprapedal groove line and reach the dorsomedial groove. Dorsomedial groove almost absent, visible only near the shell, thin, white. Caudal horn dorsal and lateral surfaces light brown, base white. Colouration of anterior lateral foot area 
under the shell and the head the area above suprapedal groove line similar to colouration of the posterior lateral foot area, but scattered. Both mantle lobes are uniformly gray-brown. Right shell lappet fan shaped, black spotted, especially on the base, near the pneumostome, in some paratypes. Left shell lappet overlain above the head with small black spots in some paratypes. In life cephalopodium darker. Pigmentation in some paratypes gray to black instead of brown.

Mantle cavity organs (Digital Appendix 1: Fig. 10, Table 3): As described for the genus.

Reproductive system (Fig. 11, Fig. 12, Digital Appendix 1: Fig. 11, Fig. 12, Fig. 13, Table 4): As in the genus and subgenus except for the following differences. Atrium with 7 to 8 internal ring folds parallel to atrium width. Penial gland rudimentary specially the middle part and the inner end. However, the inner end is expanded in an internal bilobuled penial gland, in some specimens it does not seem glandular; main lobule pillow-shaped; secondary lobule J-shaped, placed to one side of the main lobule. Without penial pads. Prepuce valve absent. Internal penial gland bi-lobulated. Lower part of the penis wall also with one longitudinal pilaster between vagina entrance and the internal penial gland's main lobe.

Penis caecum medium size, relatively broad. Verge with one side slightly curved near the base and a lateral pore that opens in middle part of the verge. Prepuce with three or four narrow parallel transversal pilasters, prepuce valve absent. Penis retractor muscle sometimes absent. Velum poorly developed, white and black. Epiphallus U-shaped, sometimes almost straight. Vas deferens attached from one side of the atrium to the other side of the vagina by a thread-like part of velum. Talon small, digitiform, slightly curved, not exposed. Hermaphroditic duct broader near albumen gland, slightly bent in the middle not coiled, end attaching to ovotestis narrower.
Dentition (Digital Appendix 1: Fig. 14, Fig. 15, Fig. 16, Fig. 17): Jaw as in the subgenus. Dentition formula: 22-13-1-13-22. Teeth as in the genus.

Type locality: Costa Rica, San José, Pérez Zeledón, Estación Biológica Las Nubes de Santa Elena. 1210 masl. 09²3'42.8980" N \& $83^{\circ} 35^{\prime} 44.3460$ " W.

Holotype: MZUCR-INB0001498759-01. Collected on 14 February 1996 by E. Alfaro. (T.: 43-E. Alfaro).

Paratypes (Total of 36 paratypes designated and examined): MZUCR-INB0001498759-00 (4 specimens), MZUCR-INB0001498759-02 (1 dissected specimen), MZUCRINB0001498759-03 (1 dissected specimen), MZUCR-INB 0001498759-04 (1 dissected specimen), MZUCR-INB0001498759-05 (1 dissected specimen). Same data as holotype.

MZUCR-INB0003307155 (7 specimens), MZUCR-INB0003307155-01 (1 dissected specimen), MZUCR-INB0003307155-02 (1 dissected specimen), MZUCRINB0003307155-03 (1 dissected specimen), MZUCR-INB0003307155-04 (1 dissected specimen), MZUCR-INB0003307155-05 (1 dissected specimen), MZUCRINB0003307155-06 (1 dissected specimen), MZUCR-INB0003307155-07 (1 dissected specimen), MZUCR-INB0003307155-08 (1 dissected specimen), MZUCRINB0003307155-09 (1 dissected specimen), MZUCR-INB0003307155-10 (1 dissected specimen), MZUCR-INB0003307155-11 (1 dissected specimen). Costa Rica, San José, Pérez Zeledón. Estación Las Nubes de Santa Elena. 1210 masl. 09²3'42.8980” N $-83^{\circ} 35^{\prime} 44.3460^{\prime \prime} \mathrm{W}$. Collected on 11 February 1996 by M. Segura. (T: 85-M. Segura).

MZUCR-244-06 (1 dissected specimen), MZUCR-244-07 (1 dissected specimen). Costa Rica, San José, Pérez Zeledón, Reserva Biológica Las Nubes de Santa Elena. 1360 masl. 09²3'13.6129” N \& 83³5'37.7048” W. 
Collected on 06 September 2012 by Z. Barrientos, A. Induni. (T: ZB-258).

UF-465683 (3 specimens). Costa Rica, San José. Estación Las Nubes de Santa Elena. Pérez Zeledón. 1360 masl. 09²3'13.6129" N \& 83³5'37.7048” W. Collected on 04 June 2013 by Z. Barrientos and C. Seas. (T.: ZB-283).

CNMO 4828 (3 specimens). Costa Rica, San José. Estación Las Nubes de Santa Elena. Pérez Zeledón. 1360 masl. 09²3'13.6129" N \& 83³5'37.7048" W. Collected on 04 June 2013 by Z. Barrientos and C. Seas. (T.: ZB-283).

ANSP-A477025 (2 specimens). Costa Rica, San José. Estación Las Nubes de Santa Elena. Pérez Zeledón. 1360 masl. 09²3'13.6129" $\mathrm{N} \& 83^{\circ} 35^{\prime} 37.7048^{\prime \prime}$ W. Collected on 04 June 2013 by Z. Barrientos and C. Seas. (T.: ZB-283).

Habitat, behaviour and ecological notes: Members of this species are understory tree dwellers and spend most of their time on and under shrub leaves near streams and swampy areas in mature forest. When distressed they twist their tail rapidly and vigorously getting away from enemies. They groom themselves with the radula. Dry and hot weather induce them to throw themselves from leaves. I did not observe any individuals hanging from their mucus pore, although they are able to produce mucus threads from their caudal pore. Unfavourable weather conditions do not induce epiphragm production. They are sympatric with Tikoconus alosii and other euconulid snails and semislugs.

Remarks: This species is similar to $T$. costaricanus in the foot coloration pattern and in lacking a white triangular area around the foot's dorsomedial groove. However, blotches look more rounded with some parts more darkly tinted and lateral foot pigmentation is present under the shell. This species is the only member of the genus with round blotches irregularly tinted.
Distribution (Fig. 14, Digital Appendix 2): This species occurs in the Reserva Biológica Las Nubes de Santa Elena, Pérez Zeledón, on the slopes of Cerro Chirripó. It is restricted to the highlands of Río Peñas Blancas basin, between 1200 and 1360 masl.

Etymology: Tikoconus onca is named after its particular foot spotted colouration pattern that recalls a jaguar, an animal that shares its habitat.

\section{Tikoconus (Tikoconus) andresi n.sp.}

Diagnosis: This species is easily recognized by its general green colour when alive. Lateral foot band pigmented from slightly above the suprapedal groove line to considerably before the dorsomedial groove, leaving a white triangle on the dorsomedial groove and a white band above the suprapedal groove line, colouration missing under the shell; suprapedal groove line black, interrupted by thin white lines, present from head to tail; subpedal groove band homogenous light gray present throughout its length; sole with one darker band in the middle running from head to tail; mantle translucent, with one difuse dark gray linear blotch above kidney's base, another difuse gray blotch covering the whole urethra's projection, some paratypes may have a third very diffuse blotch on the ovotestis; shell lappets green when alive; penis with a monolobulated internal penial gland and a prepuce valve with furry appearance; verge curved

Shell (Fig. 7, Fig. 8, Digital Appendix 1: Fig. 1, Fig. 2, Fig. 3, Fig. 4, Fig. 5, Table 1): As in the subgenus and T. costaricanus, except that shell is subglobose, light brown, approximately thickness $2.3 \mu \mathrm{m}$. Holotype whorls 3.25 , height $4.0 \mathrm{~mm}$, width $4.6 \mathrm{~mm}$, apex $0.7 \mathrm{~mm}$, transition from protoconch to teleoconch not well defined. Aperture scarcely descending in frontal view. When alive the shell is more greenish. 
External anatomy (I examined a total of 53 specimens) (Fig. 9, Fig. 10, Digital Appendix 1: Fig. 6, Fig. 7, Fig. 8, Fig. 9, Table 2): As described for the genus. Holotype cephalopodium width $2.1 \mathrm{~mm}$, length $13.0 \mathrm{~mm}$, caudal horn not obvious in dead specimens. Sole with a gray band running along the middle from head to tail. Subpedal groove band colour pattern is an uninterrupted light gray strip, present from head to caudal horn. Suprapedal groove line black broken into dashes, regularly spaced by thin white lines that do not match with all epidermis grooves; well defined from caudal horn to the head. Posterior lateral foot area background white with a dark gray narrow band between the suprapedal groove line and the dorsomedial groove, this band is regularly interrupted by very thin white lines that match with epidermis grooves, beside this, it also has a couple of dark gray blotches between lateral dark gray band and suprapedal black line. Dorsomedial groove well defined, thin, white, extending back to caudal horn, surrounded by a triangular, large, white area tapering at the caudal horn, ending at caudal horn. Caudal pore Y-shaped. Caudal horn dorsal and lateral surfaces with gray to dark gray spots, base white. Left mantle lobe has a gray area near the pneumostome, that is darker at the edge, it also has a gray band at the edge of the lobe with a small white gap above the middle groove of the head. Right shell lappet with one small gray spot at the edge. Left shell lappet margin almost straight. Left shell lappet gray spoted above pneumostome. Mantle blotch difuse gray, some paratypes also have another very diffuse blotch on the ovotestis. In life sole with middle gray line from head to tail; mantle, mantle collar and cephalopodium yellowish-green to bright green; shell lappets green.

Mantle cavity organs (Digital Appendix 1: Fig. 10, Table 3): As described for the genus.

Reproductive system (Fig. 11, Fig. 12, Digital Appendix 1: Fig. 11, Fig. 12, Fig. 13, Table 4): As in the genus and subgenus except for the following differences. Atrium with 10 to 12 poorly defined internal ring folds parallel to atrium width, two longitudinal pilasters surrounding the vagina's entrance, only one figured. Penial gland bulgy, very well-developed, especially in the middle part. Penial internal gland mono-lobulated, covered by short thin prolongations with furry appearance. Penial gland's outer end, internally concave forming a secondary caecum. Without penial pads. Verge curved, cat-claw shaped, with a subapical pore. Prepuce thick with three or four narrow transversal pilasters, end near verge's tip highly thickened forming a prepuce valve with glandular and furry appearance. Velum well developed, black, covers the whole penis sheath. Penis retractor muscle sometimes absent. Epiphallus U-shaped, bent at both ends. Vas deferens is attached from one side of the atrium to other side of the vagina by a thread-like part of velum. Talon big, digitiform, exposed. Carrefour clavate and with one cluster of acini. Hermaphroditic duct broader near albumen gland, slightly bent in the middle not coiled, end attaching to ovotestis narrower.

Dentition (Digital Appendix 1: Fig. 14, Fig. 15, Fig. 16, Fig. 18): Jaw as in the subgenus except that the cutting edge bears, sometimes, a row of tiny irregular saw-shaped teeth. This species also has the longest protruding tooth of the subgenus, but is not as long as in the subgenus Bribriconus. Dentition formula: 17-12-1-12-17. Teeth as in the genus except that the very last marginals are monocuspid, narrow, sharp, digitiform. In contrast to other Tikoconus spp. when alive, the odontophore is not red.

Type locality: Costa Rica, Limón, Talamanca. Parque Internacional La Amistad, Valle del Silencio, antes de cruzar el Río Terbi, camino a la turbera el Jardín. 2400 masl. 0907'46.7436" N \& 8257'44.9575" W.

Holotype: MZUCR-238-01; collected on 10 February 2012 by M. Zúñiga and Z. Barrientos. (T.: ZB- 244).

Paratypes (Total of 36 paratypes designated and examined): MZUCR-INB0003394593-01 
(7 specimens), MZUCR-INB0003394593-01

(1 dissected specimen), MZUCRINB0003394593-02 (1 dissected specimen), MZUCR-INB0003394593-03 (1 dissected specimen), MZUCR-INB0003394593-04 (1 dissected specimen), MZUCRINB0003394593-05 (1 dissected specimen), MZUCR-INB0003394593-06 (1 dissected specimen), MZUCR-INB0003394593-07 (1 dissected specimen), MZUCRINB0003394593-08 (1 dissected specimen), MZUCR-INB0003394593-09 (1 dissected specimen), MZUCR-INB0003394593-10 (1 dissected specimen). Costa Rica, Limón. Talamanca. Parque Internacional La Amistad. Refugio Valle Silencio. 2450 masl. 0907'14.2006" N \& 82 ${ }^{\circ} 57^{\prime} 49.9333^{\prime \prime}$ W. Collected on 18 April 2001 by A. Alvarado. (T.: 133 A. Alvarado).

MZUCR-236-01 (1 dissected specimen); MZUCR-236-02 (2 specimens). Costa Rica, Limón. Talamanca. Parque Internacional La Amistad. Alrededores Refugio Valle Silencio. 2 500 masl. $09^{\circ} 06^{\prime} 44.8879^{\prime \prime} \mathrm{N} \& 82^{\circ} 57^{\prime} 41.8021$ " W. Collected on 08 February 2012 by Z. Barrientos and M. Zúñiga. (T.: ZB-241).

MZUCR-237-01 (1 dissected specimen), MZUCR-237-02 (1 dissected specimen), MZUCR-237-03 (1 dissected specimen), MZUCR-237-04 (4 specimens), MZUCR-23705 (1 dissected specimen). Costa Rica, Limón. Talamanca. Parque Internacional La Amistad. Camino al Refugio Valle Silencio. 2500 masl. 0906'18.8773” N \& 82 $57^{\prime} 58.2274^{\prime \prime}$ W. Collected on 09 February 2012 by Z. Barrientos and M. Zúñiga. (T.: ZB-242).

MZUCR-241-01 (1 dissected specimen), MZUCR-241-02 (1 dissected specimen), MZUCR-241-03 (2 specimens). Costa Rica, Limón. Talamanca. Parque Internacional La Amistad. Camino a Cerros Tararia. 2500 masl. $09^{\circ} 08^{\prime} 57.7680^{\prime \prime} \mathrm{N} \& 82^{\circ} 57^{\prime} 54.4620^{\prime \prime} \mathrm{W}$. Collected on 12 February 2012 by Z. Barrientos and M. Zúñiga. (T.: ZB-248).

UF-465684 (3 specimens). Costa Rica, Limón. Talamanca. Parque Internacional La Amistad. Camino al Refugio Valle Silencio. 2 500 masl. $09^{\circ} 06^{\prime} 18.8773^{\prime \prime} \mathrm{N} \& 82^{\circ} 57^{\prime} 58.2274^{\prime \prime}$
W. Collected on 09 February 2012 by Z. Barrientos and M. Zúñiga. (T.: ZB-242).

CNMO 4730 (3 specimens). Costa Rica, Limón. Talamanca. Parque Internacional La Amistad. Camino al Refugio Valle Silencio. 2 500 masl. 906'18.8773" N \& 8257'58.2274" W. Collected on 09 February 2012 by Z. Barrientos and M. Zúñiga. (T.: ZB-242).

ANSP-A477024 (2 specimens). Costa Rica, Limón. Talamanca. Parque Internacional La Amistad. Camino a Cerros Tararia. 2500 masl. 0908'57.7680" N \& 82 $57^{\circ} 54.4620^{\prime \prime} \mathrm{W}$. Collected on 12 February 2012 by Z. Barrientos and M. Zúñiga. (T.: ZB-248).

Habitat, behaviour and ecological notes: This species can be found living in oak forest understory in the highlands of the Talamanca mountain range. In areas where wind is strong and temperature lower, $T$. andresi can be found among leaves accumulated on Greigia silvicola, a terrestrial bromeliad. On the contrary, in areas where the climate is warmer and less windy, they can be found mainly on leaves of palm shrubs in the family Cyclanthaceae. They do not groom themselves with the radula as other species in the genus do. Moreover, in similar weather conditions, they do not hang from their mucus pore as $T$. costaricanus does, they only withdraw their head in the shell leaving the foot exposed. However, under this situation they secrete a mucus thread from their caudal pore that attaches them to the leaves. When they reactivate, the thread is stretched until it breaks: they do not turn around to break it with the radula. The mucus thread is produced almost constantly and when they fall or throw themselves from the leaves, the thread holds them; to free themselves they move their foot vigorously until the thread breaks and they fall. If distressed they also move their foot rapidly and vigorously and throw themselves from leaves. When they travel, their body has a rhythmic lateral swing. They are sympatric with $T$. costaricanus.

Remarks: This species is similar to $T$. thompsoni in the presence of a black suprapedal 
groove line from head to tail and a large protruding tooth on the jaw, though it is not as large nor as broad in $T$. thompsoni. It differs by the presence of a homogenous gray subpedal groove band and by the absence of deep wrinkles on both sides of the jaw middle area that set off a large, broad, ridge. This species is the only one with a homogenous gray subpedal groove band and general green colour when alive.

Distribution (Fig. 14, Digital Appendix 2): This species occurs in the Talamanca mountain range, in the high lands of the Atlantic slope, in the río Terbi basin. Specimens can be found from 2400 to 2500 masl.

Etymology: Tikoconus andresi is named after Andrés Monge Barrientos, my son, who is always ready for field work, the remoter the place the happier he goes.

\section{Tikoconus (Tikoconus) katyae n.sp.}

Diagnosis: Lateral foot band pigmented from slightly above suprapedal groove line to considerably before dorsomedial groove, leaving a white triangle on dorsomedial groove, colouration missing under the shell; suprapedal groove line white, occasionally with one or two small gray rectangles near the caudal horn; subpedal groove band almost white but with some small gray blotches in the posterior end); sole white; mantle translucent, without blotches or spots; shell lappets with a narrow well defined dark gray to black distal band; penis with a mono-lobulated internal penial gland, bi-lobulated pad above internal penial gland; prepuce without valve; verge conic, straight and slender.

Shell (Fig. 7, Fig. 8, Digital Appendix 1: Fig. 1, Fig. 2, Fig. 3, Fig. 4, Fig. 5, Table 1): As in the subgenus and T. costaricanus, except that shell is subglobose slightly depressed, light brown-yellowish, approximately thickness $5.3 \mu \mathrm{m}$. Holotype whorls 3, height $2.8 \mathrm{~mm}$, width $4.0 \mathrm{~mm}$, apex $0.5 \mathrm{~mm}$, transition from protoconch to teleoconch undefined. Aperture scarcely descending in frontal view. When alive the shell is more yellowish.

External anatomy (I examined a total of 47 specimens) (Fig. 9, Fig. 10, Digital Appendix 1: Fig. 6, Fig. 7, Fig. 8, Fig. 9, Table 2): As in the description of the genus. Holotype cephalopodium width $1.6 \mathrm{~mm}$, length $10.8 \mathrm{~mm}$. Subpedal groove band colour pattern composed of very few badly defined gray blotches more abundant near the caudal end, almost absent in the anterior part, blotches of some paratypes are rectangular, darker and better defined near caudal end and lighter and badly defined or absent near the head. Suprapedal groove line completely white from the head to the caudal horn. Posterior lateral foot area with a narrow dark gray band starting slightly above suprapedal groove line and ending fairly before dorsomedial groove. Dorsomedial groove well defined, thin, extending back to caudal horn, surrounded by a large, white area tapering at caudal horn, ending at or slightly before caudal horn. Both mantle lobes are white, with a relatively thin dark gray well defined band at the edge. The left mantle lobe also has a gray blotch at the base above the right optical tentacle. Both shell lappets have a thin, well defined black band at the edge. Right shell lappet tongue shaped, covering a big part of the apex. Mantle without blotches or line on the kidney area. In life, mantle, mantle collar, shell lappets and cephalopodium white to light yellow.

Mantle cavity organs (Digital Appendix 1: Fig. 10, Table 3): As described for the genus.

Reproductive system (Fig. 11, Fig. 12, Digital Appendix 1: Fig. 11, Fig. 12, Fig. 13, Table 4): As in the genus and subgenus except for the following differences. Atrium with 7 internal ring folds parallel to atrium width. Penial gland middle part slightly underdeveloped, especially near the penial gland outer end. Internal penial gland mono-lobulated with a non-glandular bi-lobulated pad. Penial pad's main lobule cylindrical closely attached to 
the internal penial gland and placed above it; penial pad's secondary lobule triangular not well-separated from the main lobule. Penis caecum digitiform, wide. Verge slender, straight, with a subapical pore. Prepuce sometimes with a longitudinal U-shaped pilaster surrounding the verge; prepuce valve absent. Velum very thin and loose. Penis retractor muscle short and thick. Penis sheath thin, firm and muscular in all its length. Epiphallus oval shaped, bent at both ends. Vas deferens attached to penis's base by a velum thread that goes from one side of the atrium to the other side of the atrium. Talon clavate, slightly exposed. Carrefour with one cluster of acini.

Dentition (Digital Appendix 1: Fig. 14, Fig. 15, Fig. 16, Fig. 19): Jaw as in the subgenus. Dentition formula: 23-13-1-13-23. Teeth as in the genus.

Type locality: Costa Rica, Limón, Parque Nacional Braulio Carrillo, Sector Quebrada González, Sendero Las Palmas. 463 masl. $10^{\circ} 09^{\prime} 42.2760$ ” N \& 835' $16.1820^{\circ}$ ” W.

Holotype: MZUCR-234-01. Collected on 27 June 2011 by Z. Barrientos, A. Monge, E. Monge and M. Zúñiga. (T.: ZB-237).

Paratypes (Total of 40 paratypes designated and examined): MZUCR-234-02 (1 dissected specimen), MZUCR-234-03 (2 specimens). Same data as holotype.

MZUCR-230-01 (1 dissected specimen), MZUCR-230-02 (1 dissected specimen). Costa Rica, Limón. Parque Nacional Braulio Carrillo, Sector Quebrada González, Sendero el Ceibo. 463 masl. $10^{\circ} 09^{\prime} 45.9720^{\prime \prime} \mathrm{N} \&$ 8356'21.6420" W. Collected on 03 September 2010 by M. Zúñiga and G. Pérez. (T.: ZB-212).

MZUCR-243-01 (1 dissected specimen), MZUCR-243-02 (1 dissected specimen), MZUCR-243-03 (6 specimens), MZUCR-24304 (1 dissected specimen), MZUCR-243-05 (1 dissected specimen). Costa Rica, Limón, Parque Nacional Braulio Carrillo, Sector Quebrada González, Sendero Botarramas. 460 masl. 1009'45.9720" N \& 8356'21.6420” W. Collected on 30 April 2012 and 02 May 2012 by A. Induni, E. Naranjo, Z. Barrientos and M. Zúñiga. (T.: ZB 252).

MZUCR-245-01 (1 dissected specimen), MZUCR-245-02 (1 specimen). Costa Rica, Limón, Parque Nacional Braulio Carrillo, Sector Quebrada González, Senderos Botarramas y Ceibo. 445 masl. $10^{\circ} 09^{\prime} 26.7480^{\prime \prime} \mathrm{N} \&$ $83^{\circ} 56^{\prime} 35.7120^{\prime \prime}$ W. Collected on 04 October 2012 by M. Zúñiga. (T.: ZB-262).

MZUCR-247-01 (1 dissected specimen), MZUCR-247-02 (1 dissected specimen), MZUCR-247-03 (1 dissected specimen), MZUCR-247-04 (1 dissected specimen), MZUCR-247-05 (1 dissected specimen), MZUCR-247-06 (7 specimens). Costa Rica, Limón, Parque Nacional Braulio Carrillo, Sector Quebrada González, Sendero Botarramas. 463 masl. 1009'26.7480" N \& 8356'35.7120" W. Collected on 06 February 2013 by Z. Barrientos, J. Monge, M. Zúñiga and $\mathrm{A}$. Induni. (T.: ZB-274).

UF-465685 (4 specimens). Costa Rica, Limón, Parque Nacional Braulio Carrillo, Sector Quebrada González, Sendero Botarramas. 463 masl. 1009'26.7480" N \& 8356'35.7120" W. Collected on 06 February 2013 by Z. Barrientos, J. Monge, M. Zúñiga and $\mathrm{A}$. Induni. (T.: ZB-274).

CNMO 4731. (4 specimens). Costa Rica, Limón, Parque Nacional Braulio Carrillo, Sector Quebrada González, Sendero Botarramas. 460 masl. $10^{\circ} 09^{\prime} 45.9720^{\prime \prime} \mathrm{N} \& 8^{\circ} 56^{\prime} 21.6420^{\prime \prime}$ W. Collected on 30 April 2012 and 02 May 2012 by A. Induni, E. Naranjo, Z. Barrientos and M. Zúñiga. (T.: ZB-252).

ANSP-A477027 (3 specimens). Costa Rica, Limón, Parque Nacional Braulio Carrillo, Sector Quebrada González, Sendero Botarramas. 463 masl. 1009'26.7480" N \& 8356'35.7120" W. Collected on 06 February 2013 by Z. Barrientos, J. Monge, M. Zúñiga and A. Induni. (T.: ZB-274).

Habitat, behaviour and ecological notes: This species lives on understory leaves near creeks or temporary brooks with well-developed canopy in mature forest. They feed on algae and moss growing on leaves. This species 
can swing the cephalopodium rapidly and vigorously when distressed. No epiphragm is produced. Instead, dry and hot weather induce them to hang from the distal part of their foot with mucus produced by their caudal pore. The way they hang is slightly different from $T$. costaricanus because more of the sole surface is attached to the leaf and the mucus pore is seldom attached to the leaf. They are sympatric with other euconulid snails and semislugs, but not with other species of Tikoconus, according to current records.

Remarks: This species resembles $T$. subsilvanus in the presence of a black line on distal edge of shell lappets but its black line is narrower and the subpedal groove band is almost white. This species looks lighter than the others in the genus, and is the only one with a welldefined black line on the distal edge of the shell lappets. Dissection of the reproductive system will clarify any doubt of its identity as the size of the verge and shape of the internal penial glands are different.

Distribution (Fig. 14, Digital Appendix 2): This species occurs in the Braulio Carrillo National Park, restricted to Quebrada Molinete surroundings. Specimens can be found from 445 to 580 masl, which is relatively low, compared to other species in the genus.

Etymology: Tikoconus katyae is named after Katya Calderón for her outstanding labor promoting research and her constant support and friendship.

\section{Tikoconus (Tikoconus) alosii n.sp.}

Diagnosis: Lateral foot band pigmented from fairly above suprapedal groove line to considerably before dorsomedial groove, leaving a white triangle on dorsomedial groove, coloration missing under the shell; suprapedal groove line composed of poorly defined gray rectangles or blotches, more numerous near the caudal horn, almost absent near the head and middle part of the foot; subpedal groove band well defined gray rectangles higher than broad slightly shift in head's direction, band slightly lighter near head and darker near caudal horn; sole with two dark lines, located on the outer ends; mantle translucent, snow white dots around the urethra's projection and heart, some paratypes have a very thin, short and interrupted dark line at the kidney's base; shell lappets without special coloration; penis with a monolobulated internal penial gland; bi-lobulated pad above internal penial gland; prepuce with valve; verge conic, straight and sturdy.

Shell (Fig. 7, Fig. 8, Digital Appendix 1: Fig. 1, Fig. 2, Fig. 3, Fig. 4, Fig. 5, Table 1): As in the subgenus and T. costaricanus, except that shell is subglobose slightly-depressed, light brown, approximately thickness $3.6 \mu \mathrm{m}$. Holotype whorls 3.25 , height $3.4 \mathrm{~mm}$, width $4.9 \mathrm{~mm}$, apex $0.4 \mathrm{~mm}$, transition from protoconch to teleoconch not well defined. Periostome slightly curved in lateral view. Aperture not descending in frontal view. When alive the shell is more yellowish.

External anatomy (I examined a total of 73 specimens) (Fig. 9, Fig. 10, Digital Appendix 1: Fig. 6, Fig. 7, Fig. 8, Fig. 9, Table 2): As in the description of the genus. Holotype cephalopodium width $1.8 \mathrm{~mm}$, length 11.7 $\mathrm{mm}$. Sole with two dark lines, located on the outer ends. Subpedal groove band colour pattern composed of well-defined gray rectangles higher than wide, upper part shifted anteriorly, well defined near the caudal horn but lighter near the head band. Suprapedal groove line composed of poorly defined gray rectangles or blotches, more numerous near the caudal horn, almost absent near the head and middle part of the foot. Posterior lateral foot area colour pattern: background white, black band starting fairly above suprapedal band and ending considerably before dorsomedial groove. Dorsomedial groove well defined, thin, extending back to tail horn, surrounded by a triangular large white band tapering at caudal horn, finishing at or slightly before caudal horn. Caudal pore plus-shaped. Caudal horn dorsal surface 
gray, lateral surface dark gray and base surface light gray. Both mantle lobes are white with a well-defined black line at the margin, darker at the edge. Right shell lappet fan shaped, leaves the apex free; holotype with small dark blotches in the right shell lappet edge (some paratypes without dark blotches). Left shell lappet margin almost straight; holotype with few small dark blotches on the edge, some paratypes without dark blotches. Mantle blotch above urethra projection absent, but with snow white dots around the urethra's projection and heart, some paratypes also have a very thin, short and interrupted dark line at the kidney's base. In life sole lines darker.

Mantle cavity organs (Digital Appendix 1: Fig. 10, Table 3): As described for the genus.

Reproductive system (Fig. 11, Fig. 12, Digital Appendix 1: Fig. 11, Fig. 12, Fig. 13, Table 4): As in the genus and subgenus except for the following differences. Atrium with 5 to 8 very rudimentary internal ring folds parallel to atrium width. Penial gland's inner end poorly developed, but expanded in an internal monolobulated penial gland, in some specimens it does not seem glandular. Internal penial gland with a non-glandular bi-lobulated pad. Penial pad's main lobule elongated, originates from the internal penial gland and is placed between the internal penial gland and the prepuce valve; penial pad's secondary lobule J-shaped placed to one side of the main lobule. Penis caecum digitiform. Verge straight, sturdy, with an apical pore. Prepuce without transversal pilasters, surrounds verge tightly, prepuce valve present. Velum poorly developed. Epiphallus sometimes U-shaped, sometimes elongated. Vas deferens attached to penis' base by a velum thread that goes from one side of atrium to the other side of the vagina or penis. Talon clavate, slightly exposed. Carrefour with one cluster of acini.

Dentition (Digital Appendix 1: Fig. 14, Fig. 15, Fig. 16, Fig. 20): Jaw as in the subgenus. Dentition formula: 22-15-1-15-22. Teeth as in the genus.

Type locality: Costa Rica, San José. Estación Las Nubes de Santa Elena, Pérez Zeledón. 1360 masl. 09²3'13.6129” N \& 8335'37.7948" W.

Holotype: MZUCR-244-01. Collected on 6 July 2012 by Z. Barrientos and A. Induni. (T.: ZB-258).

Paratypes (Total of 43 paratypes designated and examined): MZUCR-244-02 (1 dissected specimen), MZUCR-244-03 (1 dissected specimen), MZUCR-244-04 (1 dissected specimen), MZUCR-244-05; (5 specimens) same data as holotype.

MZUCR-INB0003300073 (3 specimens), MZUCR-INB0003300073-01(1 dissected specimen), MZUCR-INB0003300073-02 (1 dissected specimen). Costa Rica, San José, Pérez Zeledón, Estación Las Nubes de Santa Elena, Finca El Gringo. 1300 masl. 09²3'31.5050” N \& 83³5'42.7100” W. Collected on 29 September 1995 by B. Gamboa. (T.: 36 B. Gamboa).

MZUCR-INB0003307156 (18 specimens), MZUCR-INB0003307156-01 (1 dissected specimen), MZUCR-INB0003307156-02 (1 dissected specimen), MZUCR-INB0003307156-03 (1 dissected specimen), MZUCRINB0003307156-04 (1 dissected specimen), MZUCR-INB0003307156-05 (1 dissected specimen), MZUCR-INB0003307156-06 (1 dissected specimen). Costa Rica, San José, Pérez Zeledón, Estación Las Nubes de Santa Elena. 1210 masl. 09²3'42.8980" N \& $83^{\circ} 35^{\prime} 44.3460$ " W. Collected on 11 February 1996 by M. Segura. (T.: 85-M. Segura).

UF-465686 (2 specimens). Costa Rica, San José. Estación Las Nubes de Santa Elena. Pérez Zeledón. 1360 masl. 09²3'13.61292” N \& $83^{\circ} 35^{\prime} 37.79484$ " W. Collected on 4 June 2013 by Z. Barrientos and C. Seas. (T.: ZB-283).

CNMO 4732 (2 specimens). Costa Rica, San José. Estación Las Nubes de Santa Elena. Pérez Zeledón. 1360 masl. 09²3'13.6129" N \& 83³5'37.7948" W. Collected on 4 June 2013 by Z. Barrientos and C. Seas. (T.: ZB-283). 
ANSP-A477022 (2 specimens). Same data as holotype.

Habitat, behaviour and ecological notes: This species lives on leaves of understory shrubs near streams and swampy areas in mature forest. When distressed they move their tail rapidly and vigorously, escaping from possible enemies. They groom themselves with the radula. They do not produce an epiphragm. Instead, dry and hot weather induces them to throw themselves from leaves. I have not observed this species hanging from its mucus pore, but they are able to produce a mucus thread from their caudal pore. They are sympatric with Tikoconus onca and other euconulid snails and semislugs.

Remarks: The foot colour pattern is similar in T. alosii and T. subsilvanus, but T. alosii lacks a black line on shell lappets distal edge. This species is the only one with a broad black line on the distal margin of the shell lappets.

Distribution (Fig. 14, Digital Appendix 2): This species occurs in the Reserva Biológica Las Nubes de Santa Elena, Pérez Zeledón, on the slopes of Cerro Chirripó. It is restricted to the highlands of Río Peñas Blancas basin. They have been found from 1210 to 1500 masl.

Etymology: Tikoconus alosii is named after the priest Adolfo López de la Fuente, S.J., known as Alosi, for his friendship, for sharing his enthusiasm in neotropical malacofauna research and for all our intellectual exchange.

\section{Tikoconus (Tikoconus) subsilvanus n.sp.}

Diagnosis: Lateral foot band pigmented from slightly above suprapedal groove line to considerably before dorsomedial groove, leaving a white triangle on dorsomedial groove, colouration missing under the shell; suprapedal groove line with very few, weakly-defined gray blotches; subpedal groove band with well-defined gray rectangles from head to tail; sole white; mantle translucent, one small black linear blotch along the kidney's base; shell lappets with a broad diffuse dark gray to black distal band; penis with a mono-lobulated internal penial gland; no additional pads; prepuce very long, without valve but with a slender S-shaped pilaster; verge conic and straight.

Shell (Fig. 7, Fig. 8, Digital Appendix 1: Fig. 1, Fig. 2, Fig. 3, Fig. 4, Fig. 5, Table 1): As in the subgenus and T. costaricanus, except that shell is subglobose slightly-depressed, light brown, approximately thickness $3.8 \mu \mathrm{m}$. Holotype whorls 3.5 , height $3.8 \mathrm{~mm}$, width $5.0 \mathrm{~mm}$, apex $0.5 \mathrm{~mm}$, transition from protoconch to teleoconch not well defined. Periostome slightly curved in lateral view. Aperture descending in frontal view. When alive the shell is more yellowish.

External anatomy (I examined a total of 12 specimens) (Fig. 9, Fig. 10, Digital Appendix 1: Fig. 6, Fig. 7, Fig. 8, Fig. 9, Table 2): As in the description of the genus. Holotype cephalopodium width $1.7 \mathrm{~mm}$, length $9.3 \mathrm{~mm}$. Subpedal groove band colour pattern of welldefined gray rectangles higher than wide, upper part shifted anteriorly, rectangles are darker near the caudal horn and lighter near the head. Suprapedal groove line has very few poorly defined and irregularly spaced gray blotches in all its length. Posterior lateral foot area with a narrow dark gray band starting slightly above suprapedal groove line and ending fairly before dorsomedial groove. Dorsomedial groove well defined, thin, white, from head to caudal horn, surrounded by a triangular large white area tapering at caudal horn, ending before caudal horn. Caudal horn dorsal surface black, lateral surface gray and basal surface white. Both mantle lobes white with a broad, well defined black line at the edge. Both shell lappets with a broad distal black band, in some parts (especially the right shell lappet) the band is broader and diffuse. Right shell lappet circle shaped. Mantle without a blotch above the urethra projection, but with a small black line-shaped blotch along the kidney's base. 
Mantle cavity organs (Digital Appendix 1: Fig. 10, Table 3): As described for the genus.

Reproductive system (Fig. 11, Fig. 12, Digital Appendix 1: Fig. 11, Fig. 12, Fig. 13, Table 4): As in the genus and subgenus except for the following differences. Atrium with 6 rudimentary internal ring folds parallel to atrium width. Penial gland very rudimentary, surrounds less than half of the penis circumference, covers half of the penis length at the most. Penial gland middle part poorly developed. Penial gland's inner end rudimentary, expanded in a poorly-developed internal domeshaped mono-lobulated penial gland, although it is not clearly glandular. Without penial pads. Penis caecum large, digitiform. Verge straight, with an apical pore. Prepuce thin, between two and three times verge's length, without transversal pilasters, with an internal stylized S shaped pilaster in the lower part of the prepuce, prepuce valve absent. Velum sometimes absent, black. Epiphallus elongated or U-shaped. Vas deferens attached to penis' base by a velum thread that goes from one side of the atrium to the other side. Talon: digitiform, exposed.

Dentition (Digital Appendix 1: Fig. 14, Fig. 15, Fig. 16, Fig. 21): Jaw as in the subgenus. Dentition formula: 20-12-1-12-20. Teeth as in the genus.

Type locality: Costa Rica, Alajuela. Parque Nacional Tenorio, Bijagua, Upala. Sector Estación Río Celeste, sendero a la cañería. 932 masl. $10^{\circ} 41^{\prime} 48.00^{\prime \prime} \mathrm{N} \& 85^{\circ} 00^{\prime} 42^{\prime \prime} \mathrm{W}$.

Holotype: MZUCR-246-01. Collected on 27 November 2012 by Z. Barrientos and M. Zúñiga. (T.: ZB-269).

Paratypes (Total of 10 paratypes designated and examined): MZUCR-246-02 (1 dissected specimen). Same data as holotype.

MZUCR-INB003719962-01 (1 dissected specimen). Costa Rica, Guanacaste. Z.P. Tenorio. Río San Lorenzo, Tierras Morenas. 1000 masl. 10³6’37.6510" N \& 8459'41.8760” W. Collected on 09 July 1996 by G. Rodríguez. (T: 6-G. Rodríguez).
MZUCR-INB0003719965-01 (1 dissected specimen), MZUCR-INB0003719965-02 (1 dissected specimen). Costa Rica, Guanacaste. Z. P. Tenorio. Tilarán, Tierras Morenas, Cerca de las Faldas del Volcán Tenorio. 1100 masl. $10^{\circ} 37^{\prime} 16.6340 ”$ N \& 8500'18.1480” W. Collected on 12 July 1996 by G. Rodríguez. (T: 9-G. Rodríguez).

MZUCR-248-01 (1 dissected specimen), MZUCR-248-02 (1 dissected specimen). Costa Rica, Alajuela. Parque Nacional Tenorio, Bijagua, Upala. Sendero a la cañería. 1128 masl. 1041'46" N \& 85'00'55" W. Collected on 5 March 2013 by Z. Barrientos and C. Seas. (T.: ZB-275).

MZUCR-249-01 (1 dissected specimen), MZUCR-249-02 (1 specimen). Costa Rica, Alajuela. Parque Nacional Tenorio, Bijagua, Upala. Sendero a Tenorio II. 1229 masl. $10^{\circ} 41^{\prime} 49.90^{\prime \prime} \mathrm{N} \& 85^{\circ} 01^{\prime} 08.5^{\prime \prime} \mathrm{W}$. Collected on 5 March 2013 by A. Monge, Z. Barrientos and C. Seas. (T.: ZB-286).

UF-465687 (1 specimen). Costa Rica, Alajuela. Parque Nacional Tenorio, Bijagua, Upala. Sendero a Tenorio II. 1229 masl. 1041'49.90" $\mathrm{N} \& 85^{\circ} 01$ '08.5" W. Collected on 5 March 2013 by A. Monge, Z. Barrientos and C. Seas. (T.: ZB-286).

CNMO 4830 (1 dissected specimen). Costa Rica, Alajuela. Parque Nacional Tenorio, Bijagua, Upala. Sendero a Tenorio II. 1229 masl. 1041'49.90" N \& 8501'08.5" W. Collected on 5 March 2013 by A. Monge, Z. Barrientos and C. Seas. (T.: ZB-286).

Habitat, behaviour and ecological notes: Understory dwellers on shrubs leaves and small palms in mature forest. They can be found on and under leaves, but they are considerably rare. They move their tail rapidly and vigorously when distressed and throw themselves from the leaves, getting away from possible enemies. They groom themselves with the radula. They do not produce an epiphragm, instead, dry and hot weather induce them to throw themselves from leaves. These snails hang from mucous threads by their mucus pore and sole's caudal 
area. While hanging they keep their head and tentacles withdrawn in the shell.

Remarks: It is similar to T. alosii by the foot colour pattern, but differentiates from it by the presence of a black line on shell lappets distal edge. It is also similar to T. katyae by the presence of a black line on shell lappets distal edge, but its black line is broader and the subpedal groove band is darker and better defined and runs from head to tail. This species is the only one with a broad dark line on shell lappets distal edge, therefore its right shell lappet is the darkest. Dissection of the reproductive system will clarify any doubt of its identity as verge size and internal penial glands shape are different.

Distribution (Fig. 14, Digital Appendix 2): This species occurs on the flanks of Volcán Tenorio, from 900 to 1250 masl.

Etymology: Tikoconus subsilvanus is named after its natural habitat, as they live in dark understory with a well-developed canopy.

\section{Bribriconus, subg. nov.}

Type species: Tikoconus (Bribriconus) thompsoni $\mathrm{n} . \mathrm{sp}$. The subgenus is monotypic.

Diagnosis: The subgenus Bribriconus can be distinguished from subgenus Tikoconus by its thicker shell (around $14 \mu \mathrm{m}$ thick) (Fig. 15 ), which is rigid when the snail is alive. Jaw angulated in cutting edge view, middle area forming a conspicuous, broad, flat longitudinal ridge, differentiated from the lateral arms of the jaw by deep wrinkles and an abrupt angle change that gives the angular appearance of the jaw; the cutting edge bears a broad, projecting protruding tooth but is otherwise, smooth (Fig. 15). This subgenus can also be identified by the atrium without bulges and a middle part of the penis differentiated and with internal pads.

Comparison: The subgenus Bribriconus is similar to the subgenus Tikoconus in its external and internal anatomy. However, the thickness and rigidity of the shell are clearly different. Also, the angular shape of the jaw and the lack of bulges in the atrium differentiate Bribriconus from Tikoconus.

Etymology: The subgenus Bribriconus refers to the Bribri indigenous people that original inhabit Tikoconus (Bribriconus) thompsoni type locality, and to "conus" from the latin word for cone.

\section{Tikoconus (Bribriconus) thompsoni, n.sp.}

Diagnosis: This species is distinguished by its rigid and relatively thick shell in comparison to members of subgenus Tikoconus, and by its colour pattern: lateral foot band pigmented starting slightly above suprapedal line ending at dorsomedial groove near caudal end and slightly before dorsomedial groove near shell, leaving a small white triangular area on the back near the shell, pigmentation present under shell; suprapedal groove line black from head to tail; subpedal groove band gray from head to tail, formed by irregular rectangles higher than broad and slightly shifted in head direction, band slightly lighter near head and darker near caudal horn; sole white; mantle translucent, one black linear blotch along the kidney's base, a second blotch covering more than half of the urethra's projection, and some specimens with a black blotch under the protoconch whorls; shell lappets with a snow white, irregularly dotted line on the distal edge; penis with a mono-lobulated internal penial gland; prepuce short, surrounds verge loosely, with a valve; prepuce valve with a sausage-shaped extension; a pad that above the internal penial gland and a second pad that covers part of the external penial gland middle part; verge conic and straight.

Shell (Fig. 7, Fig. 8, Digital Appendix 1: Fig. 1, Fig. 2, Fig. 3, Fig. 4, Fig. 5, Table 1): The main shell difference from members of subgenus Tikoconus is its thickness. Although the shell is thin, approximately $14 \mu \mathrm{m}$, it is 


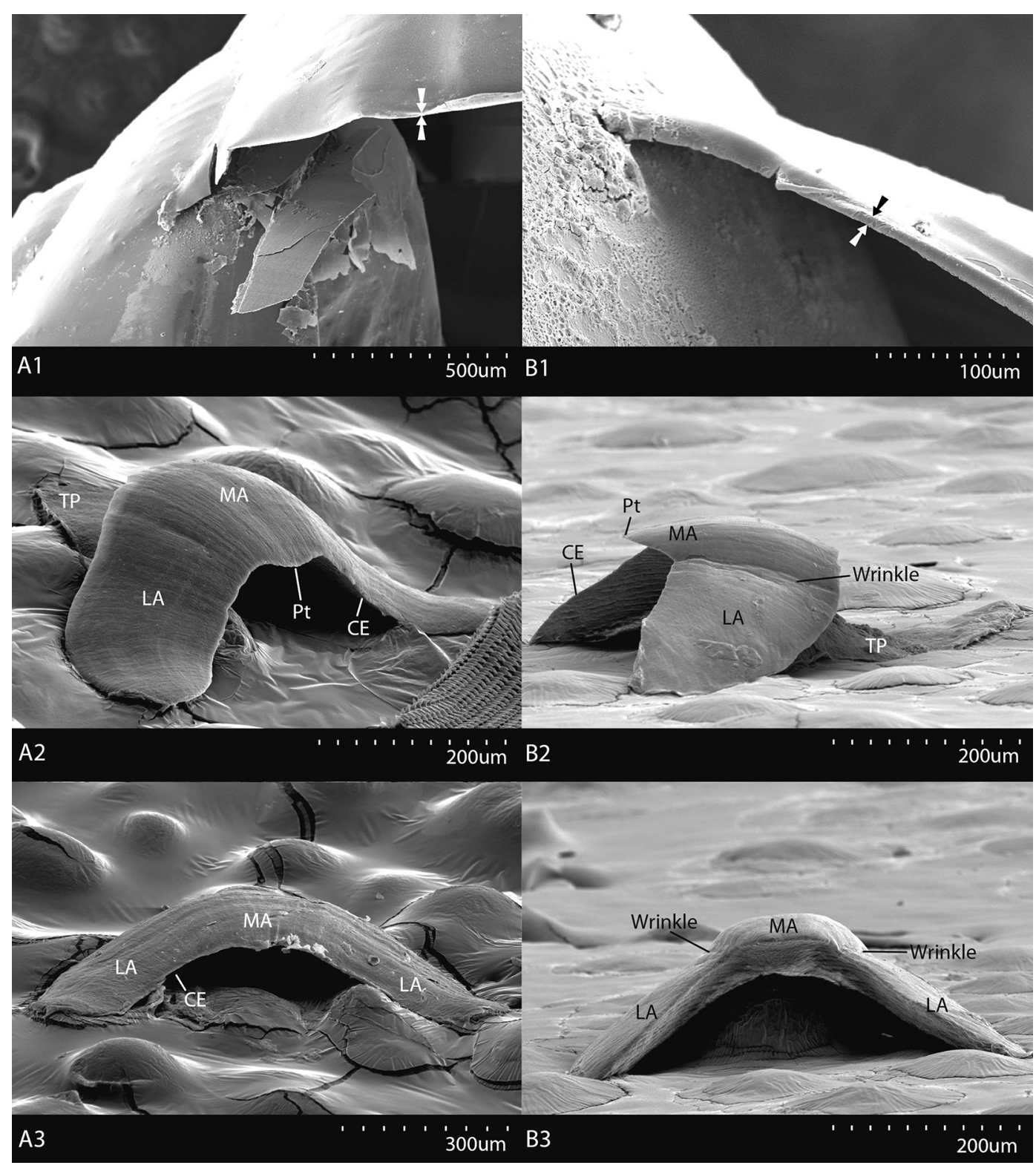

Fig. 15. Subgeneric characteristics of Tikoconus. A: Tikoconus, T. (T.) costaricanus. B: Bribriconus, T. (B.) thompsoni. 1-Notice the thickness of the outer lip. 2-Jaw lateral view. 3-Jaw cutting edge view. CE - cutting edge; Pt - protruding tooth; LA - lateral arm; MA - middle area; TP - median ridge.

approximately four times the thickness of the shell in the subgenus Tikoconus. Therefore, $T$. thompsoni is the only species of the genus in which the shell is rigid enough to separated it from the body without breaking it.
Holotype whorls 3.5 , height $3.5 \mathrm{~mm}$, width $4.2 \mathrm{~mm}$, apex $0.5 \mathrm{~mm}$, transition from protoconch to teleoconch not well defined. Other characteristics of the species include a subglobose, dark corneous brown, translucent 
and fragile shell. Aperture height/width ratio 1.22 , scarcely descending in frontal view.

External anatomy (I examined a total of 37 specimens) (Fig. 9, Fig. 10, Digital Appendix 1: Fig. 6, Fig. 7, Fig. 8, Fig. 9, Table 2): As in the description of the genus. Holotype cephalopodium width $1.6 \mathrm{~mm}$, length 10.5 $\mathrm{mm}$. Subpedal groove band colour pattern: composed of a gray band from head to caudal horn, interrupted by very thin white lines forming poorly defined rectangles higher than wide shifted anteriorly, darker near the caudal horn. Suprapedal groove line black broken in to dashes, spaces between dashes are very thin white lines, well defined from the head to the caudal horn. Posterior lateral foot area colour matches epidermis texture with white grooves and dark gray ridges, forming a broad dark gray band that starts slightly above suprapedal groove line and ends at dorsomedial groove near the caudal end and slightly before dorsomedial groove near the shell. Dorsomedial groove well defined, thin, extending back to caudal horn, surrounded by a short, triangular, white area, tapering at caudal horn, but ending fairly before caudal horn. Caudal horn dorsal surface black, lateral surface gray, basal surface white. Anterior lateral foot area colour similar to colouration of the posterior lateral foot area, but scattered and not reaching the shell. Both mantle lobes with a broad black band formed by black spots. Both shell lappets have a slender and irregular "snow white" band at the edge, some snow white spots sprinkled and some black spots around the pneumostome. Holotype lost the snow-white band with time in alcohol. Right shell lappet tongue shaped. Left shell lappet with some black blotches above the right optical tentacle, it also has some snow white spots sprinkled, that were lost with time in alcohol. Mantle's blotch covers more than half of the urethra projection, some paratypes with a black blotch under the protoconch whorls. In life shell lappets yellowish with an irregular line of snow white dots covering the whole edge forming a "V, cephalopodium colour pattern much darker when alive.
Mantle cavity organs (Digital Appendix 1: Fig. 10, Table 3): As described for the genus.

Reproductive system (Fig. 11, Fig. 12, Digital Appendix 1: Fig. 11, Fig. 12, Fig. 13, Table 4): As in the genus and subgenus except for the following differences. Atrium without internal ring folds, accessory bulges absent. Penial gland covers about $1 / 4$ of the atrium. Penial gland's inner end well developed but not spherical or protruding. Internal penial gland mono-lobulated, spherical, small and covered by two internal shallow pillow-shaped pads. Penial main pad placed above the internal penial gland and expanded upwards covering the middle part of the penis internal wall until the prepuce valve; penial secondary pad placed beneath the main pad and above part of the middle part of the external penial gland. Penis caecum large, digitiform, rests above the penial gland's outer end. Verge slightly curved, slender, with an apical pore. Prepuce thick, surrounds verge loosely, forming a capsule, with two transversal pilasters, prepuce valve present with a sausage-shaped pad attached to the lower penial wall that reaches the caecum opening and a second pillow-shaped pad placed beneath the first one. Velum poorly developed. Penis sheath thin and muscular in all its length. Epiphallus elongated. Vas deferens loosely attached to penis' base and to vagina by several thin velum threads, sometimes a thicker one goes from one side of the vagina or penis to the other side. Talon digitiform, slightly curved, exposed.

Dentition (Digital Appendix 1: Fig. 14, Fig. 15, Fig. 16, Fig. 22): Jaw as in subgenus Bribriconus. Dentition formula: 25-11-1-11-25. Teeth as in the genus, except that the mesocone of the last marginal teeth are about three times larger.

Type locality: Costa Rica, Puntarenas. Parque Internacional La Amistad. Márgenes de la quebrada La Mina, Estación Altamira sendero a Casa Coca. 1450 masl. $09^{\circ} 01^{\prime} 54.7260^{\prime \prime}$ $\mathrm{N} \& 83^{\circ} 00^{\prime} 22.1700^{\prime} \mathrm{W}$. 
Holotype: MZUCR-252-01. Collected on 15 November 2012 by Z. Barrientos and M. Zúñiga. (T: ZB-265).

Paratypes (Total of 18 paratypes designated and examined): MZUCR-252-02 (1 dissected specimen), MZUCR-252-03 (1 dissected specimen), MZUCR-252-04 (1 dissected specimen). Same data as holotype.

MZUCR-INB0001484414-01 (1 dissected specimen). Costa Rica, Puntarenas. Parque Internacional La Amistad. Estación Altamira. 1 300 masl. 0901'58.7526" N \& 8300’39.1728" W. Collected on 10 April 1995 by L. Angulo. (T: 25-L. Angulo).

MZUCR-253-01 (1 dissected specimen), MZUCR-253-02 (1 dissected specimen), MZUCR-253-03 (1 dissected specimen), MZUCR-253-04 (1 dissected specimen), MZUCR-253-05 (1 dissected specimen), MZUCR-253-06 (1 dissected specimen), MZUCR-253-07 (1 specimen). Costa Rica, Puntarenas. Parque Internacional La Amistad, Estación Altamira, camino al tajo, río Sábalo (La Mina). 1140 masl. 0901'10.9800" N \& $83^{\circ} 00^{\prime} 35.5860$ " W. Collected on 16 November 2012 by Z. Barrientos and M. Zúñiga. (T.: ZB-268).

MZUCR-254-01 (1 dissected specimen). Costa Rica, Puntarenas. Parque Internacional La Amistad, Estación Altamira, sendero los Gigantes del Bosque. 1400 masl. $09^{\circ} 01^{\prime} 47.6700^{\prime} \mathrm{N} \& 83^{\circ} 00^{\prime} 35.5300^{\prime \prime} \mathrm{W}$. Collected on 15 November 2012 by Z. Barrientos and M. Zúñiga. (T.: ZB-266).

MZUCR-255-01 (1 specimen). Costa Rica, Puntarenas. Parque Internacional La Amistad. Orilla quebrada Congo, Estación Altamira sendero a Pittier. 1360 masl. $09^{\circ} 02^{\prime} 22.9020^{\prime \prime} \mathrm{N}$ \& 82 $58^{\prime} 28.1160^{\prime}$ W. Collected on 14 November by 2012 by Z. Barrientos and M. Zúñiga. (T: ZB-264).

UF-465688 (2 specimens). Same data as holotype.

CNMO 4827 (2 specimens). Costa Rica, Puntarenas. Parque Internacional La Amistad. Orilla de río Claro, camino al tajo 1200 masl.
0901'22.9320” N \& 8300'11.1180” W. Collected on 16 November 2012 by Z. Barrientos and M. Zúñiga. (T.: ZB-267).

ANSP-A477026 (1 specimen). Same data as holotype.

Habitat, behaviour and ecological notes: This species inhabits the understory of mature and old secondary forests near streams. Members of this species feed on epiphytes of Piperaceae shrubs, palms and Heliconia leaves. They do not hang from their mucus pore during dry weather, but the caudal pore excretes a mucus thread. The snails break the mucus thread by pulling while crawling. If they are exposed to sunlight, they move rapidly to the underleaf and withdraw their right shell lappet inside their shell; sometimes they throw themselves into the leaf litter. They groom themselves with the radula and are able to twist their tail when distressed but compared to the other species, they do not twist it as vigorously.

Remarks: This species is similar to $T$. andresi in the presence of a black suprapedal groove line from head to tail, the shape of the shell, and the presence of a large jaw protruding tooth, though it is noticeably broader and larger in T. thompsoni. This species sometimes has very long shell lappets, reminding Velifera, however, the shell lappets of Velifera do not cover the protoconch whorls. Also, the shell shape is similar to Velifera, but with a slightly shorter spire and a straight and larger aperture (Fig. 16).

Distribution (Fig. 14, Digital Appendix 2): This species occurs on highlands of río Sábalo and río Canasta. Specimens can be found between 1100 to 1700 masl.

Etymology: Tikoconus thompsoni is named after the late Fred G. Thompson, University of Florida, for his kindness and teaching in my earliest malacological steps. 


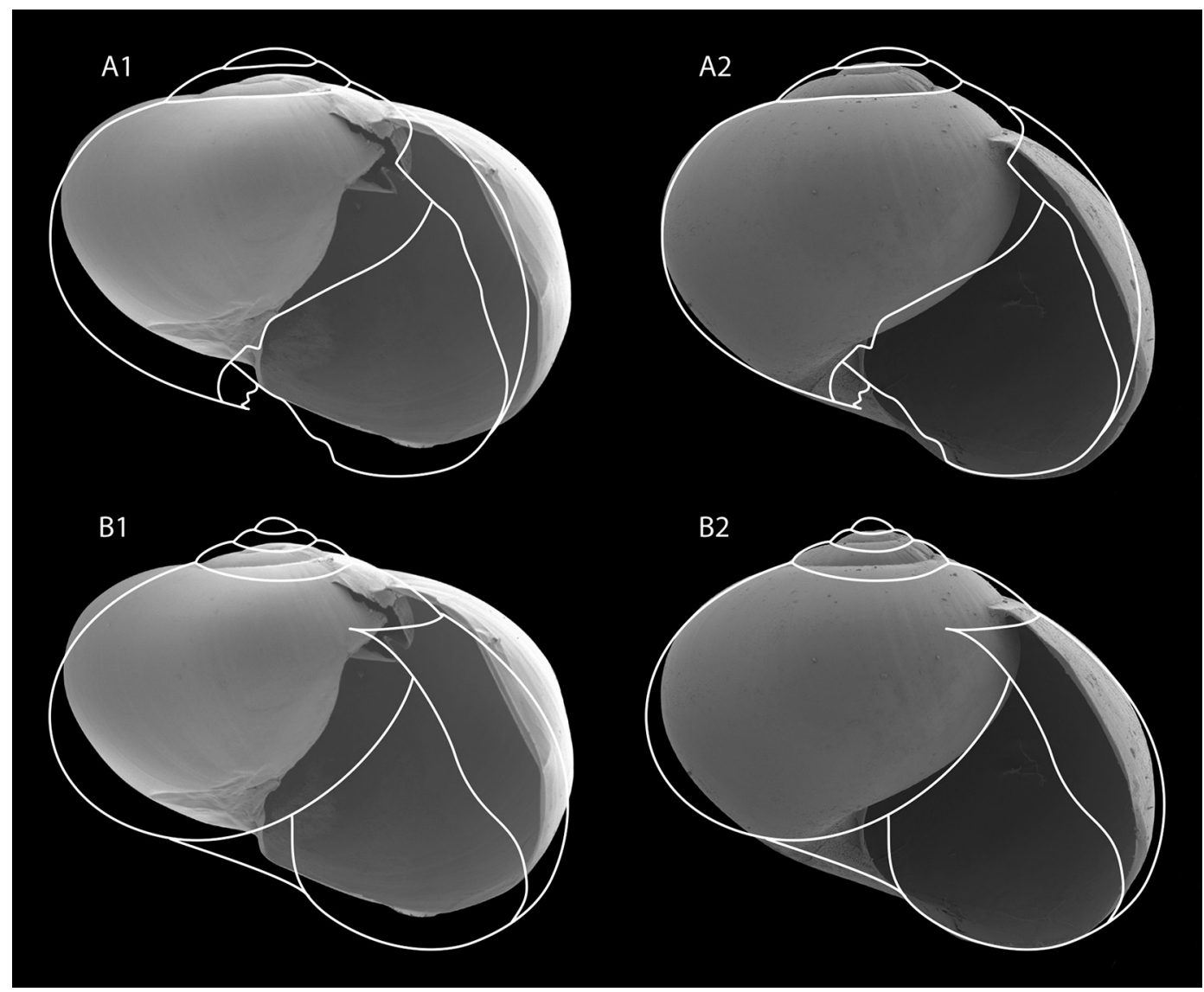

Fig. 16. Comparison of Velifera gabbi 's outline made from (A) the lectotype's photograph and from (B) the shell in the original publication of $V$. gabbi and the shell of Tikoconus (Tikoconus) costaricanus (1) and of Tikoconus (Bribriconus) thompsoni (2).

\section{DISCUSSION}

Stylommatophora monophyly is well documented and accepted (Barker, 2001; Wade \& Mordan, 2000; Wade, Mordan, \& Naggs, 2006), but relationships within the Stylommatophora are still in debate (Emberton et al., 1990; Barker, 2001; Wade, Mordan, \& Clarke, 2001; Wade et al., 2006). No phylogenetic analysis within the euconulid genera has been performed. All classification work has relied on morphology, but secondary loss of morphological characters complicates the task. I follow Schileyko (2002a, 2002b) and assign the new genus within the Euconulidae, subfamily Euconulinae.
There are 10 genera or subgenera of Euconulinae that occur in Central America: Euconulus Reinhard, 1883, Dryachloa Thompson \& Lee, 1980, Guppya Mörch, 1867, Pseudoguppya Baker, 1925, Euconulops Baker, 1928, Habroconus P. Fischer \& Crosse, 1872, Cocosconus Baker 1941, Cocoslens Baker, 1941, Ernstia Jousseaume, 1889 and Velifera Binney, 1879.

The general appearance, the presence of a strongly modified penis caecum, the absence of spermatheca and the location of the oviduct and perivaginal gland puts this genus close to Pseudoguppya, a subgenus of Euconulus. Nevertheless, it differs by: verge being in the penis and not in the vas deferens' entrance to 
epiphallus; penis sheath not surrounding the penial caecum; penial retractor being attached to the epiphallus, not to the penial sheath; presence of penial gland; shell height lower and not angulated, and postnuclear whorls without spiral threadlets.

The presence of the verge entering the penis also occurs in three other subgenera in the Euconulus clade: Pseudoguppya, Guppya and Euconulops. The genus Guppya differs from Tikoconus by the spermatheca presence and penial sheath covering the base of the penis caecum. The epiphallus of Euconulops also reminds me of Tikoconus due to its axial plicae and verge entering the penis, but Euconulops has a spermatheca and the epiphallus has a thicker wall.

General shell shape of Tikoconus is slightly similar to Dryachloa in its depressed profile, short spire and rounded last whorl, but it differs from it by its very short spire and falling oblique aperture. Spiral striae are also present in the embryonic whorls of Euconulus, Guppya, Euconulops, Habroconus, Cocosconus and Cocoslens, but none of them has a smooth surface in later whorls.

In relation to Euconulinae from other parts of the world, Tikoconus should be compared with Gunongia Tillier \& Bouchet, 1988 and Afroconulus Van Mol \& van Bruggen, 1971 from Borneo and SE Africa. These genera, like all American euconulinae genera, have a perivaginal gland in a basal position. The genus Gunongia also has a conic penial caecum, a conic verge in the penis and an ovate epiphallus.

The semislug appearance is uncommon in the Euconulinae; there are only three described genera with this particular morphology: Sabalimax from Borneo, with a reduced internal shell; Velifera from Costa Rica, with a thin and fragile external shell; and Tikoconus.

\section{Comparison with Velifera Binney, 1879}

Shape and coloration patterns of the cephalopodium, mantle and mantle processes in American euconulids are taxonomically important, though they are seldom described. As the original Velifera description has a good drawing of the live specimen and considering that it is also a Costa Rican euconulid semislug, I made a detailed comparison.

Only one species was described in this genus: Velifera gabbi Binney, 1879. In the 19th century William Gabb collected some specimens in Costa Rica. Some of these specimens were preserved in "spirits" (probably alcohol) and provided to W.G. Binney. Binney`s description is based on Gabb's original drawings of the living specimen and on the jaw and lingual dentition that Binney extracted and examined himself (Binney, 1879). Unfortunately, the specimens were dried up before internal parts were described.

I choose the specimen ANSP 48765, which is the best preserved syntype, as lectotype of Velifera gabbi, with the purpose of clarifying the application of the name to a taxon. This specimen was drawn by Schileyko (2002a), photographed by the Academy of Natural Sciences (http://clade.ansp.org/malacology/collections/search.php?submitbut=Search\&name $=\&$ location $=$ \&agent $=\&$ catalog $=48765)$ and is also shown as outline drawings (Fig. 16, Fig. 17) and photographs (Fig. 18A, Fig. 18B) in this paper.

Gabb collected V. gabbi at 1000 masl; today the area is highly urbanized and it is difficult to collect material at that altitude. I have visited the type locality on more than 15 occasions and collected some euconulids, including some $T$. costaricanus at 2000 masl, but I could not find $V$. gabbi.

The drawing of the shell of $V$. gabbi in Binney's paper differs from the lectotype in having one more whorl, a more tapering spire, a less inflated last whorl and a straight suture in the aperture (Fig. 17A, Fig. 17B). Probably, Binney used a different syntype to illustrate the species, but remainder syntypes are too damaged to be useful. The shell size given by Binney is difficult to interpret: greater diameter $6 \mathrm{~mm}$, lesser $5 \mathrm{~mm}$, height $3 \mathrm{~mm}$. These measurements correspond to a considerably flatter shell than the one illustrated by him. Schileyko (2002a) published another drawing of a syntype, probably the same that I chose as 
lectotype because it is the best preserved specimen. This drawing shares the same differences with Binney's drawing that I pointed before for the lectotype, except that the aperture's columellar wall is more concave (Fig. 17C). The lectotype's columellar wall is broken, this explains the difference between Schileyko's drawing and the lectotype photograph and outline, but it is very probable that Schileyko's drawing was made from the lectotype (Fig. 16, Fig. 17, Fig. 18A). Schileyko (2002a) adds to the original description the following shell characteristics: very fragile, last whorl inflated, evenly round at periphery, embryonic whorls smooth, later whorls with very weak irregular radial wrinkles, aperture ample. Neither Binney, nor Schileyko mention that the internal shell layer is slightly nacreous, similar to Tikoconus, a characteristic that can only be seen in very small areas of the syntypes due to their deterioration (Fig. 18B). They also did not mention that the embryonic whorls are not completely smooth. In Velifera, the first half of the embryonic whorls, and in Tikoconus the first quarter whorl, are smooth, but then become spirally striate (Fig. 18C, Fig. 18D), the number of striae is similar in both genera; the remaining whorls are smooth as described by Binney and Schileyko.

The jaw description of Velifera matches Tikoconus; however, the information given by Binney is not enough for comparison with the subgenera of Tikoconus. Velifera's central, lateral and marginal teeth are very similar to Tikoconus; bicuspid marginal teeth are the main identification character in the subfamily Euconulinae (Baker, 1928). The dentition formula of $V$. gabbi given by Binney 30-12-112-30 does not match any species of Tikoconus, but is similar to them. However, it is puzzling that Binney illustrated a marginal tooth and labelled it as number " 42 " in a species that only has 30 marginal teeth.

I found two drawings of the living snail with considerable differences: one was published with the original description (Fig. 19A) and the other is kept in the ANSP with the lectotype and syntypes (Fig. 19B). The most outstanding differences in the unpublished drawing are that the shell is wider; the spire shorter, the foot larger, the black squares of the suprapedal groove line more numerous and the space between them shorter, the labial tentacle is shorter, the right and left shell lappets are slightly shorter and the head is thinner. It is important to notice that although the unpublished drawing shows a flatter shell, it is still too high for the shell measurements that Binney gave in his paper. Although, both pictures show the left side of the living snail, a small part of the right shell lappet can be seen. Therefore, this lappet must be very long, otherwise it would be impossible to see the right shell lappet from the left side of the snail. It also must
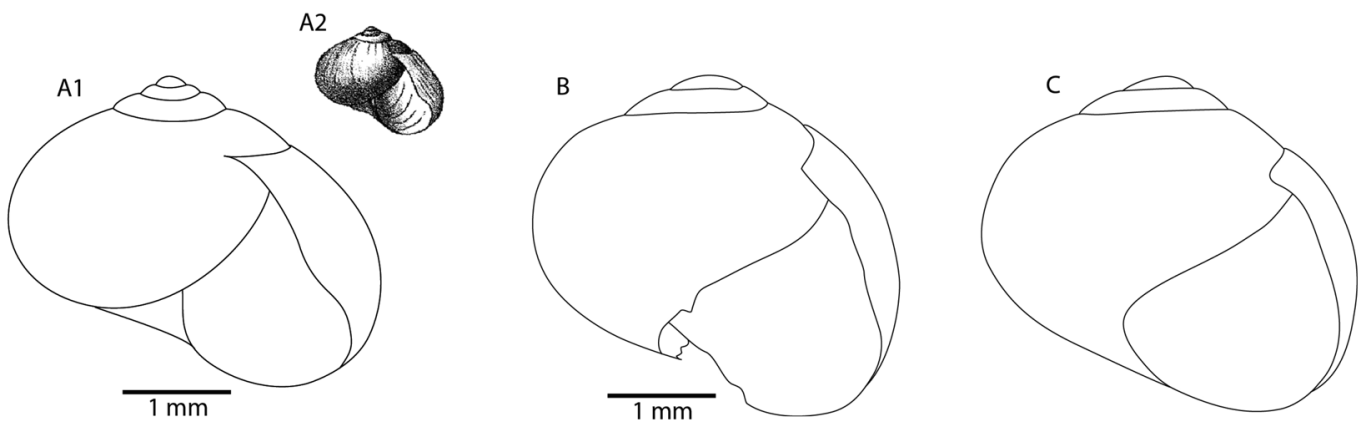

Fig. 17. Shell of Velifera gabbi: A1: Outline of the drawing of the shell published by Binney (1879); A2: Reproduction of the drawing published in the species description (Binney, 1879); B: Outline of the lectotype photograph (http://clade.ansp. org/malacology/collections/search.php?submitbut=Search\&name=\&location=\&agent=\&catalog=48765 and Fig. 19); C: Drawing of a syntype, probably the one that is designed as lectotype (Schileyko, 2002a) scale absent in the original paper, size of the specimen is $3.8 \times 4.5 \mathrm{~mm}$. 

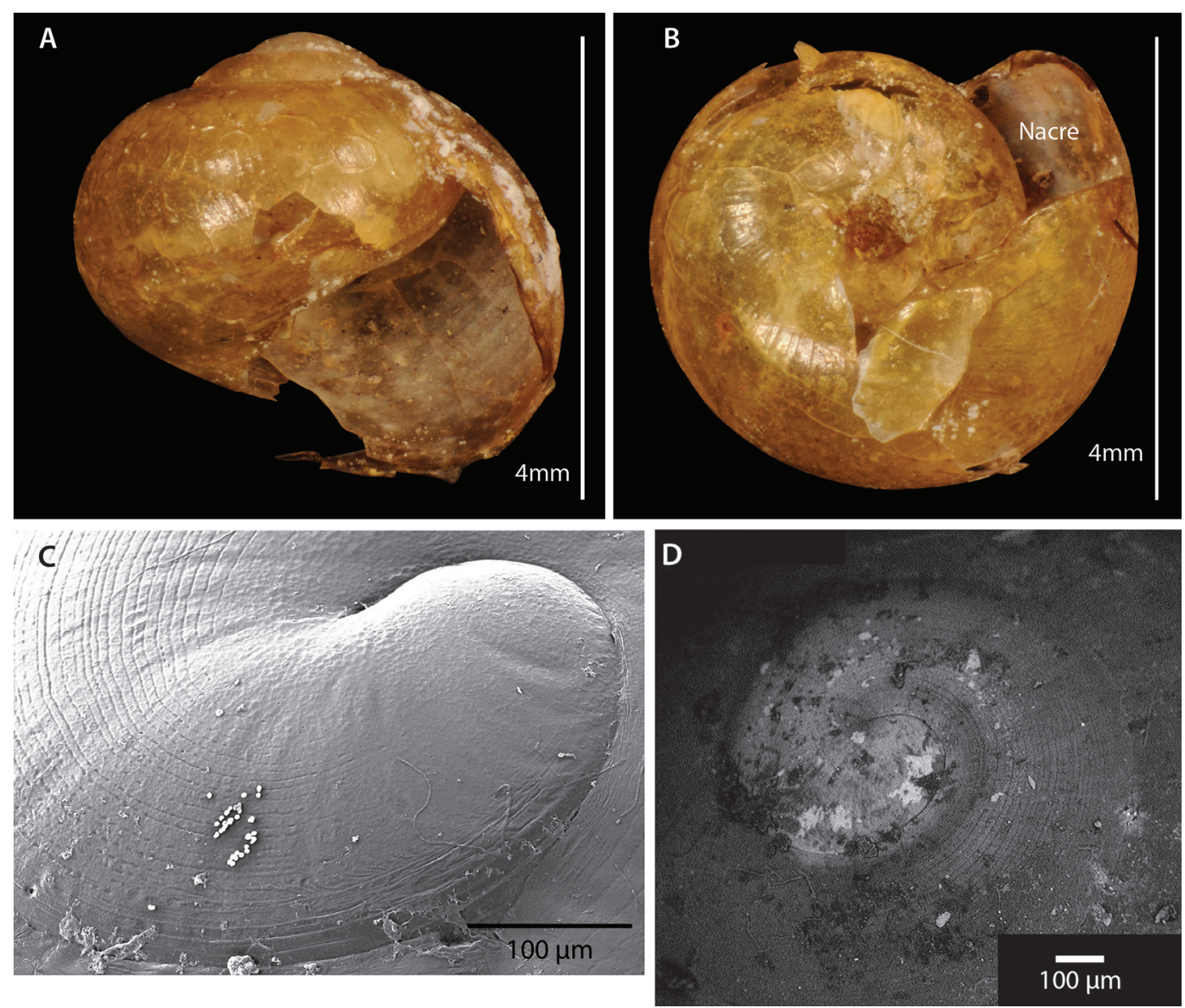

Fig. 18. A: Lectotype of Velifera gabbi; B: Internal nacre in V. gabbi. C: embryonic whorls of T. costaricanus; D: embryonic whorls of $V$. gabbi.

be placed in different position, as it covers part of the body whorl but not the apex. In contrast, when seeing the left side of the subgenus Tikoconus, the right shell lappet cannot be seen easily, it covers just a small part of the apex and leaves the body whorl free (Fig. 19C). The subgenus Bribriconus has a large right shell lappet, therefore, when seen from the left side, it covers the whole apex and part of the body whorl (Fig. 19D). Consequently, in a hypothetic right side view of the living snail the right shell lappet must have a different development and position (Fig. 19E, Fig. 19F). Other differences with the genus Tikoconus, according to Gabb's drawings, are that in Velifera the mantle lobes are absent, the suprapedal groove line is broader and uniformly coloured from head to tail, the head is probably white or at least not dark, the back part of the foot has a broader white or at least not pigmented area and the cephalopodium is considerably narrow at the end. I analysed the syntypes of $V$. gabbi many years ago, and one of the syntypes still had the dried up body, I can add that the caudal horn was present, contrary to what Binney stated in his original description. However, this feature was lost some years after my observation due to further deterioration of the syntypes in the collection (David Robinson and Francisco Borrero, pers. com.). When alive, several euconulids change the size and appearance of their caudal horn according to speed and activity 


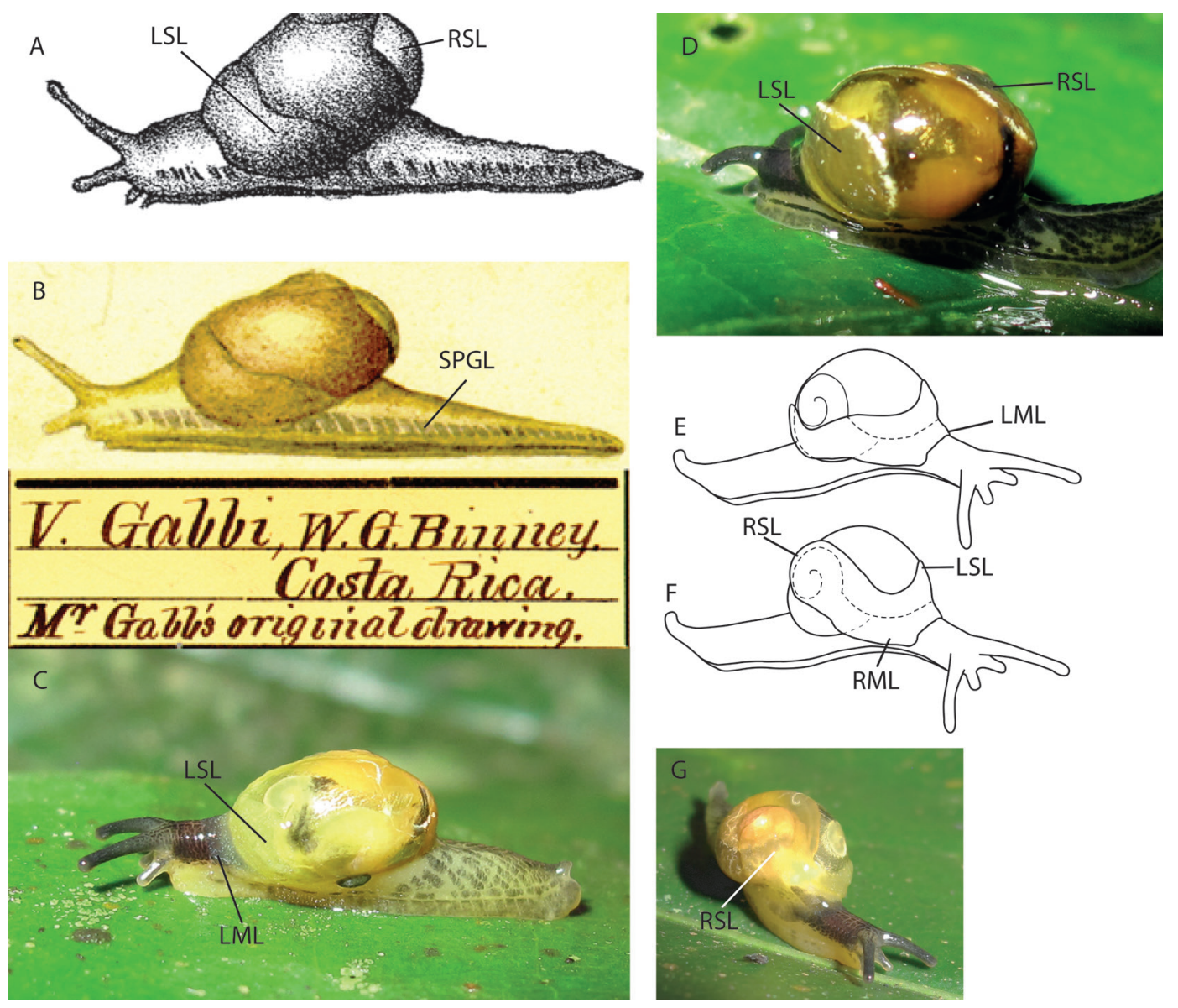

Fig. 19. A: Reproduction of Velifera gabbi drawing of the description paper (Binney 1879); B: Gabb's unpublished drawing of $V$. gabbi; C: Living specimen of $T$. (T.) costaricanus, left side view; D: Living specimen of $T$. (B.) thompsoni, left side view; E: Hypothetic right side view of $V$. gabbi; F: Schematic view of the right side of Tikoconus sp. G: Front view of T. (T.) costaricanus. For abbreviations see Fig. 3.

and sometimes it is almost imperceptible (pers. obs.). Therefore, it is possible that the caudal horn passed unnoticed.

The genus Velifera resembles Tikoconus by its general semislug appearance, few whorls, large aperture, inflated last whorl, nacre inside the shell, long cephalopodium, shell lappets covering shell partially, jaw almost smooth with a median ridge in the convex side, teeth shape, caudal horn presence, spiraly striae in part of the embryonic whorl, amount of striae in the embryonic whorl and the behavioral characteristic of twisting their tail vigorously when distressed. It differs from Tikoconus by the embryonic whorls being smooth in the first half whorl instead of the first quarter; the oblique and falling aperture; the cephalopodium shape being broad near the shell and tapering posteriorly; the foot and head coloration pattern; the absence of mantle lobes and the right shell lappet position (Fig. 16, Fig. 17, Fig. 18, Fig. 19). The genus Velifera is probably closely related to Tikoconus, especially to the subgenus Bribriconus, it could even be that the genus Velifera and the subgenus Bribriconus are synonymous. However, the affinities of Velifera cannot be better discussed until live specimens are collected to study their internal anatomy. Until then, Velifera should be kept as a valid monotypic genus. 


\section{Key to Tikoconus subgenera based on external anatomy}

1a. Shell very thin and flexible when alive; jaw middle area not differentiated from lateral arms by deep wrinkles; jaw convex in cutting edge view; jaw protruding tooth small;

Tikoconus sensu stricto atrium with bulges on female and male sides

1b. Shell thin and rigid when alive; jaw middle area differentiated from lateral arms by deep Bribriconus wrinkles; jaw angular in cutting edge view; jaw protruding tooth large; atrium without bulges on female and male sides

\section{Key to Tikoconus species base on external anatomy}

1a. Shell dark amber, rigid; foot dorsum with a small white triangle from shell to the middle part of

T. thompsoni the foot (it does not reached the caudal horn)

1b. Shell yellow amber, flexible; foot dorsum either with a long white triangle from shell to caudal horn or without a white triangle

2a. Dorsomedial groove without a white triangular area (lateral pigmentation reaches dorsomedial groove)

2b. Dorsomedial groove surrounded by a white triangular area tapering towards caudal horn direction and reaching it

3a. Lateral foot band pigmentation not present under shell, rest of the foot with a gray to black band formed by rectangles

3b. Lateral foot band pigmentation present under shell, spot-shaped blotches

T. onca

4a. Shell lappets with a black line on the distal edge

5

4b. Shell lappets without a black line on the distal edge

6

5a. Shell lappet black line narrow and well defined; suprapedal groove line white from head to T. katyae tail; subpedal groove band often with very few grey spots poorly defined or dark well defined rectangles, but always almost completely absent near the head

5b. Shell lappet black, line broad and diffuse; suprapedal groove line with very few poorly defined and irregularly spaced blotches; subpedal groove band formed by a well-defined band of dark rectangles from head to tail

6a. Suprapedal groove line composed of dashes irregularly spaced, quantity of dashes varies from few to many

6b. Suprapedal groove line black regularly interrupted by very thin white lines, well defined from head to tail

T. subsilvanus

T. alosii

T. andresi 


\section{Key to Tikoconus species base on male anatomy}

1a. Atrium without bulges

T. thompsoni

1b. Atrium with bulges on both sides

2

2a. Uterus with a broad gray duct running adjacent to the prostate and along uterus

T. costaricanus and free oviduct

2b. Uterus without a broad gray duct running adjacent to the prostate and along uterus and free oviduct

3a. Internal penial gland with furry appearance

T. andresi

3b. Internal penial gland without furry appearance

4

4a. Prepuce between two and three times verge`s length

T. subsilvanus

4b. Prepuce about the same length as the verge

5

5a. Verge conic, curved

T. onca

5b. Verge conic, not curved

6

6a. Verge slender

T. katyae

6b. Verge sturdy

T. alosii

\section{ACKNOWLEDGMENTS}

I am especially grateful to Andrés Monge, Andrea Induni, Carolina Seas, Helmuth Johnson and Maribel Zúñiga for field and technical assistance. Edna Naranjo-García, Fred G. Thompson, Edmund Gittenberger, John Slapcinsky and two anonymous reviewers made valuable suggestions to improve the draft. Yolanda Camacho helped with loan of specimens from the University of Costa Rica Zoology Museum. David Robinson and Francisco Borrero helped finding the syntypes of Velifera that were misplaced in the collection for several years, made photographs and helped with observations of the syntypes. Julián Monge took care of our children, provided unconditional support and valuable advice. This paper was partially financed by the project "FEES-Conare Análisis ecosistémico para la evaluación de la restauración forestal y sus implicaciones en el secuestro de carbono en un bosque nublado" and by the UNED's Research Vice Presidency. Special acknowledgement to Katya Calderón for her administrative support.
This paper is part of the Ph.D. requirements, Doctorado en Ciencias Naturales para el Desarrollo at the Instituto Tecnológico de Costa Rica (ITCR), Universidad Nacional (UNA) and Universidad Estatal a Distancia (UNED).

\section{RESUMEN}

Un género nuevo de semibabosas (Stylommatophora: Euconulidae) de Costa Rica y revisión del género Velifera (Stylommatophora: Euconulidae). La familia Econulidae tiene distribución circumglobal, pero solo la subfamilia Euconulinae está presente en el continente americano. En Costa Rica hay reportadas 14 especies nativas de euconúlidos. En este trabajo describo el género Tikoconus g.n., un euconúlido nuevo y endémico de Costa Rica. Este género se puede reconocer por su aspecto de semibabosa, su concha externa subglobosa a subglobosa comprimida, muy delgada y flexible. La ausencia de pequeños puntos negros en el manto y la presencia de al menos algunas manchas oscuras en la banda inferior del surco pedal, junto con una prolongación en forma de $\mathrm{Z}$ de la uretra que casi alcanza el collar del manto, son distintivos del género. El sistema reproductivo tiene una glándula penial distintiva. Ésta, tiene forma de $\mathrm{C}$, rodea el pene, está adherida al pene y al ciego del pene, pero carece de ductos conectores y tiene una extensión interna en el pene mono o bilobulada. 
El epifalo tiene una verga que ingresa en el pene. La caperuza del pene rodea parte del pene, la base del epifalo y la inserción del músculo retractor del pene, deja libre la glándula penial y el ciego del pene. Carece de glándula gametolítica. Describo dos subgéneros nuevos: Tikoconus con 6 especies $T$. (T.) costaricanus sp.n. (type species), $T$. (T.) onca sp.n., T. (T.) andresi sp.n., T. (T.) katyae sp.n., T. (T.) alosii sp.n., T. (T.) subsilvanus sp.n.; y Bribriconus con una especie $T$. (B.) thompsoni sp.n. Todas las especies tienen una distribución restringida a una cuenca, la única excepción es $T$. costaricanus que vive en casi todas las cadenas montañosas de Costa Rica. Este género habita en bosques tropicales muy húmedos y poco alterados de los 400 a los $2500 \mathrm{msm}$ en la vertiente atlántica y de los 760 a los $2500 \mathrm{msm}$ en la vertiente pacífica. El género Velifera, la otra semibabosa euconúlida reportada para Costa Rica, se mantiene como un taxón válido. Escojo el espécimen ANSP 48765 como lectotipo de Velifera gabbi con el propósito de aclarar la aplicación del nombre a un taxón.

Palabras clave: Euconulinae, moluscos terrestres, semibabosa, endemismo, anatomía de moluscos.

\section{REFERENCES}

Baker, H. B. (1928). Minute American Zonitidae. Proceedings of the Academy of Natural Sciences of Philadelphia, 80, 1-44, Pl 1-8.

Baker, H. B. (1941). Zonitid snails from Pacific Islands. Parts 3 and 4. Bernice P. Bishop Museum Bulletin, 166, 205-370.

Barker, G. M. (2001). Gastropods on Land: Phylogeny, Diversity and Adaptative Morphology. In G. M. Barker (Ed.), The biology of terrestrial mollusks (pp. 1-146). New York: CABI Publishing.

Barrientos, Z. (2003). Lista de especies de moluscos terrestres (Archaeogastropoda, Mesogastropoda, Archaeopulmonata, Stylommatophora, Soleolifera) informadas para Costa Rica. Revista de Biología Tropical, 51(Supl. 3), 293-304.

Bequaert, J. C., \& Miller, W. B. (1973). Mollusks of the Arid Southwest. Tucson: University of Arizona Press.

Binney, W. G. (1879). On the jaw and lingual dentition of certain Costa Rica Land Shells collected by Dr. William M. Gabb. Annals of the New York Academy of Sciences, 1(9), 257-262, Pl. XI.

Bouchet, P., \& Rocroi, J. P. (2005). Classification and nomenclator of gastropod families. Malacologia, $47(1-2), 1-397$.
Emberton, K. C., Kunicio, G. S., Davis, G. M., Phillips, S. M., Monderewicz, K. M., \& Guo, Y. H. (1990). Comparison of recent classifications of stylommatophoran land-snail families, and evaluation of largeribosomal-RNA sequencing for their phylogenetics. Malacologia, 31(2), 327-352.

Hilje Quirós, L. (2013). Trópico agrestre: La huella de los naturalistas alemanes en la Costa Rica del siglo $X I X$. Cartago, Costa Rica: Editorial Tecnológica de Costa Rica.

Pilsbry, H. A. (1900). On the zoological position of Partula and Achatinella. Proceedings of the Academy of Natural Sciences of Philadelphia, 52, 561-567.

Pilsbry, H. A. (1946). Land Mollusca of North America (North of Mexico). Proceedings of the Academy of Natural Sciences of Philadelphia, 2(1), 1-520.

Schileyko, A. A. (2002a). Treatise on recent terrestrial pulmonate mollusks: Punctidae, Helicodiscidae, Discidae, Cystopeltidae, Euconulidae, Trochomorphidae. Ruthenica, Suppl. 2(8), 1035-1166.

Schileyko, A. A. (2002b). Treatise on recent terrestrial pulmonate mollusks: Helicarionidae, Gymnarionidae, Rhysotinidae, Ariophantidae. Ruthenica, Suppl. 2(9), 1167-1180.

Thompson, F. G. (2011). An annotated checklist and bibliography of the land and freshwater snails of Mexico and Central America. Bulletin of the Florida Museum of Natural History, 50(1), 1-299.

Vaught, K. C. (1989). A Classification of the Living Mollusca. Melbourne, Florida, USA: American Malacologists.

Wade, C. M., \& Mordan, P. B. (2000). Evolution within the gastropod molluscs: using the ribosomal RNA gene cluster as an indicator of phylogenetic relationships. Journal of Molluscan Studies, 66(4), 565-570.

Wade, C. M., Mordan, P. B., \& Clarke, B. (2001). A phylogeny of the land snails (Gastropoda: Pulmonata). Proceedings of the Royal Society of London B: Biological Sciences, 268, 413-422. DOI: 10.1098/ rspb.2000.1372

Wade, C. M., Mordan, P. B., \& Naggs, F. (2006). Evolutionary relationships among the Pulmonate landsnails and slugs (Pulmonata, Stylommatophora). Biological Journal of the Linnean Society, 87, 593-610. DOI: 10.1111/j.1095-8312.2006.00596.x

Zilch, A. (1959-1960). Handbuch der Paläozoologie: Gastropoda: Teil 2 Euthyneura. Berlin: Gebrüder Borntraeger. 